\title{
Progress in Montmorillonite Functionalized Artificial Bone Scaffolds: Intercalation and Interlocking, Nanoenhancement, and Controlled Drug Release
}

\author{
DongYing Li, Pin Li, Yong Xu $\mathbb{D}^{\mathbb{D}}$, WenMing Guo, MengQi Li $\mathbb{D}$, MeiGui Chen, HaoYu Wang, \\ and HaiMei Lin
}

\begin{abstract}
Key Laboratory of Hunan Province for Efficient Power System and Intelligent Manufacturing, College of Mechanical and
\end{abstract} Energy Engineering, Shaoyang University, Shaoyang 422000, China

Correspondence should be addressed to Yong Xu; xuyong2927@hnsyu.edu.cn and MengQi Li; sciencefield@163.com

Received 1 September 2021; Revised 18 December 2021; Accepted 20 December 2021; Published 30 January 2022

Academic Editor: Dong Kee Yi

Copyright (c) 2022 DongYing Li et al. This is an open access article distributed under the Creative Commons Attribution License, which permits unrestricted use, distribution, and reproduction in any medium, provided the original work is properly cited.

\begin{abstract}
Montmorillonite (MMT) has attracted widespread attention in the field of bone tissue engineering in recent years because of its interlayer domain structure. The progress of MMT application was reviewed in this article. Concretely, the application of MMT was mainly explained from the structural characteristics, mechanical strengthening mechanism, organic functionalization, and drug loading and release. Firstly, the polar polymer molecular chains are easily induced into the interlayer domain of MMT to form an interlock and achieve the mechanical strengthening of scaffold. Secondly, the "sandwich" sheet structure of MMT can be exfoliated into graphene-like MMT nanosheets, providing a nanostrengthening effect for polymer matrix. In addition, MMT's interlayer domain provides a favorable environment for the loading and slow release of drugs, and it is an ideal platform for the functionalization of bone scaffolds. More importantly, MMT can be easily modified by cation exchange and chemical reaction to further improve the compatibility of composites: such as strengthening mechanical interlocking and nanostrengthening effects and achieving controllable loading and release of drugs. It is expected to provide a reference for improving the application of bone tissue engineering scaffolds.
\end{abstract}

\section{Introduction}

With the increase in traffic accidents and the accelerated aging of the population, the demand for defective tissues, especially bone tissues, is increasing in recent years. Although autologous bone transplantation is still the gold standard for bone defect repair, its application is limited to a certain extent due to its limited materials, increased surgical trauma, and susceptibility to infection at the bone site $[1,2]$. Allogeneic bone transplantation also has immune rejection, low survival rate, and risks of disease transmission and cross-infection $[3,4]$. The threedimensional porous artificial bone made of biodegradable materials has many unique advantages: (1) It has a shape and structure that matches the defected part and has sufficient mechanical properties to carry the stress transfer of the damaged part; (2) it has good osteogenic properties to induce cell growth and osteogenic differentiation, without rejection; (3) it has a suitable degradation rate, which makes room for new tissue until it is completely absorbed, and finally realizes the repair and functional reconstruction of the bone defect $[5,6]$.

Commonly used bone scaffold materials include metals $[7,8]$, polymers $[9,10]$, bioceramics/glass $[11,12]$, and their composites $[5,13]$. Metal materials have excellent mechanical properties and good biocompatibility, while their modulus is much higher than that of natural bone so that it is easy to produce a stress shielding effect, which seriously affects the stability of bone repair [14]. Polymer bone scaffolds generally have the defect of insufficient mechanical properties, and synthetic polymers even lack effective bioactivity and osteogenesis function [15]. Inorganic bioceramic materials exhibit good biological properties, but they have the defect of poor fracture toughness when used alone [16]. In brief, a single type of material is difficult to meet the requirements of bone scaffold materials. 
The strategy of composite materials is expected to be compatible with the advantages of each component material while avoiding its shortcomings, thereby providing a new way for the preparation of artificial bone for bone defect repair. Natural bone is mainly composed of organic part of type I collagen and inorganic part of hydroxyapatite crystals, as well as some cells, blood vessels and a small amount of growth factors, etc. [14, 17]. Among them, organics such as collagen not only acts as the growth framework of hydroxyapatite (HA) but also acts as a biological template to regulate its nucleation and growth, so that bone tissue has a very delicate structure and excellent mechanical properties [18]. Therefore, in order to prepare artificial bone that meets the needs of bone defect repair, more and more scholars hope to realize the controllable design of the mechanical properties, degradation performance, and osteogenesis function of bone scaffolds through the combination of materials with different properties and functions. A schematic diagram of a process for bone repair using a bone scaffold was presented, as shown in Figure 1.

Montmorillonite (MMT), with a molecular formula of $(\mathrm{Na}, \mathrm{Ca}) 0.33(\mathrm{Al}, \mathrm{Mg}) 2\left(\mathrm{Si}_{4} \mathrm{O}_{10}\right)(\mathrm{OH})_{2} \cdot \mathrm{nH}_{2} \mathrm{O}$ [19], is a biodegradable monoclinic silicate mineral, which have a "sandwich" sheet structure composed of aluminum-oxygen octahedrons and silicon-oxygen tetrahedrons [20, 21]. As a typical clay mineral, it is widely used in the mechanical strengthening of bone scaffolds [22]. On the one hand, it can be transformed into graphene-like nanosheets with higher specific surface area through interlayer exfoliation behavior after undergoing chemical or physical action, so as to realize the nanostrengthening of the composite bone scaffold [23]. On the other hand, the rich cations between the layers of the MMT crystal structure have strong ion exchange capacity, which can induce the insertion of ionic polymer molecules into the interlayer domains of its "sandwich" structure through intercalation. In this way, molecular cross-linking bridges are used to achieve interlocking with the matrix, further enhancing the mechanical properties of the bone scaffold [24-27]. More importantly, through molecular intercalation and target-oriented functional modification, MMT is expected to build a drug or growth factor loading platform that realize the controlled and sustained release of loaded drugs or growth factors and the biofunctionalization of bone scaffolds [28].

The latest research progress of montmorillonite in bone tissue engineering was briefly summarized in this article. The structural characteristics and properties of MMT as well as its application potential and advantages in bone tissue engineering were first explained. The focus was on the application of montmorillonite as a nanofiller in bone scaffolds and the latest research progress in organic modification to optimize its application. Besides, future prospects and development challenges for the application of MMT in bone tissue engineering are also prospected.

\section{The Structure of Montmorillonite}

MMT is a low-cost natural clay mineral and an important component of sedimentary rock and layered silicate- derived soil [29-31]. It is often used as an adsorbent to repair environmental pollution in the engineering field and as a drug carrier in the biomedicine field [32, 33]. The microstructure of MMT is a sandwich sheet structure constructed from nanocrystals with a thickness of about $1 \mathrm{~nm}$. Specifically, its crystal lattice is composed of two O-Si-O tetrahedral flakes and one $\mathrm{O}-\mathrm{Al}(\mathrm{Mg})-\mathrm{O}$ octahedral flake, and $\mathrm{O}-\mathrm{Al}(\mathrm{Mg})-\mathrm{O}$ octahedrons and two O-Si-O tetrahedrons achieve bilateral fusion by sharing oxygen atoms, thus forming a sandwich-like interlayer $[34,35]$, as show in Figure 2.

The stability of the sandwich-like structure of MMT is mainly maintained by intermolecular forces such as van der Waals forces and electrostatic effects [23, 36]. At the same time, the intermolecular interaction force ensures the space of the interlayer domain in the steady state and provides a place for the loading of biomolecules such as antiinflammatory drugs or the intercalation of modifiers such as polymer molecules [37]. More importantly, isomorphous substitution can occur in the MMT sandwich structure to generate charges. Specifically, in tetrahedral crystals, trivalent $\mathrm{Al}^{3+}$ can replace tetravalent $\mathrm{Si}^{4+}$, and $\mathrm{Al}^{3+}$ in octahedral crystals can be replaced by divalent $\mathrm{Mg}^{2+}$, so that a large number of negative charges are generated in the interlayer domain of MMT. Moreover, these negative charges can be absorbed hydrated cations (such as $\mathrm{Na}^{+}$) into the interlaminar space to achieve the effect of charge balance $[38,39]$. Under certain conditions, these cations can be replaced by other cations; that is, cation exchange can be carried out. The phenomenon of cation exchange is expected to become the driving force for drug loading and molecular intercalation and to provide a guarantee for the functional modification of bone scaffolds.

\section{Montmorillonite Improves the Mechanical Properties of the Scaffold}

Scaffolds apply to bone tissue engineering should have strong mechanical strength as a physical support to resist internal and external pressure and at the same time provide a platform for cell adhesion, extension, proliferation, and differentiation. A single natural polymer or synthetic polymer often has insufficient mechanical properties. Therefore, it is necessary to add other materials to change this situation. In recent years, various studies have showed that the polymer matrix containing nanofillers not only has good biological properties but also has sufficient mechanical properties $[40,41]$. As a natural clay nanomaterial, MMT not only has a large specific surface area, large aspect ratio, high rigidity, and good processibility but also can be well combined with polymeric matrix materials through physical or chemical effects $[42,43]$. It has been reported that only a lower content of nanomontmorillonite filler was needed to significantly improve the mechanical properties of composite materials [38]. As shown in Table 1, some literature reported the improvement of unmodified MMT on the tensile/compressive strength and elastic strength of the polymer.

In general, the ways that MMT nanofillers enhance the mechanical properties of the polymer matrix can be summarized as follows: (1) inducing polymer molecular chains to be 


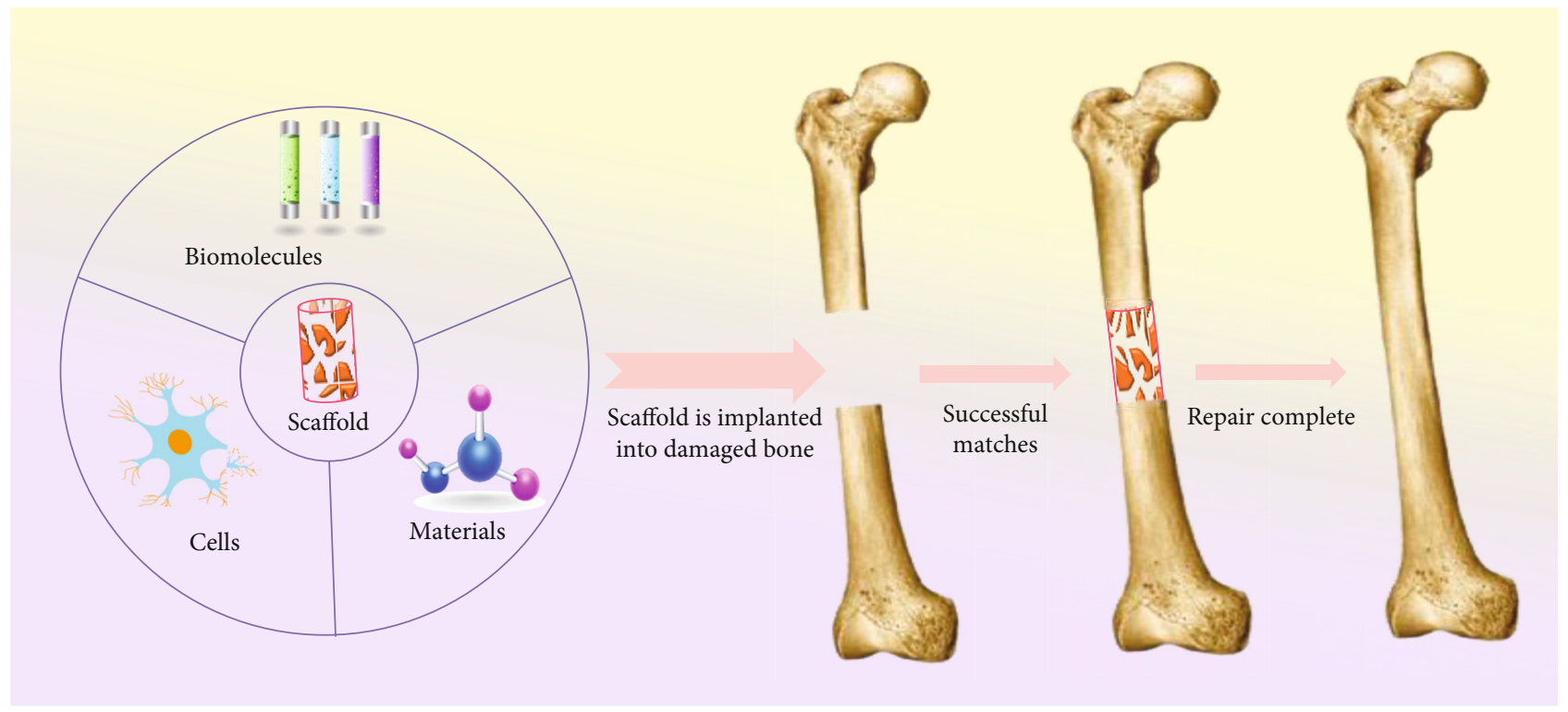

FIGURE 1: Schematic diagram of artificial bone scaffold used for bone repair.

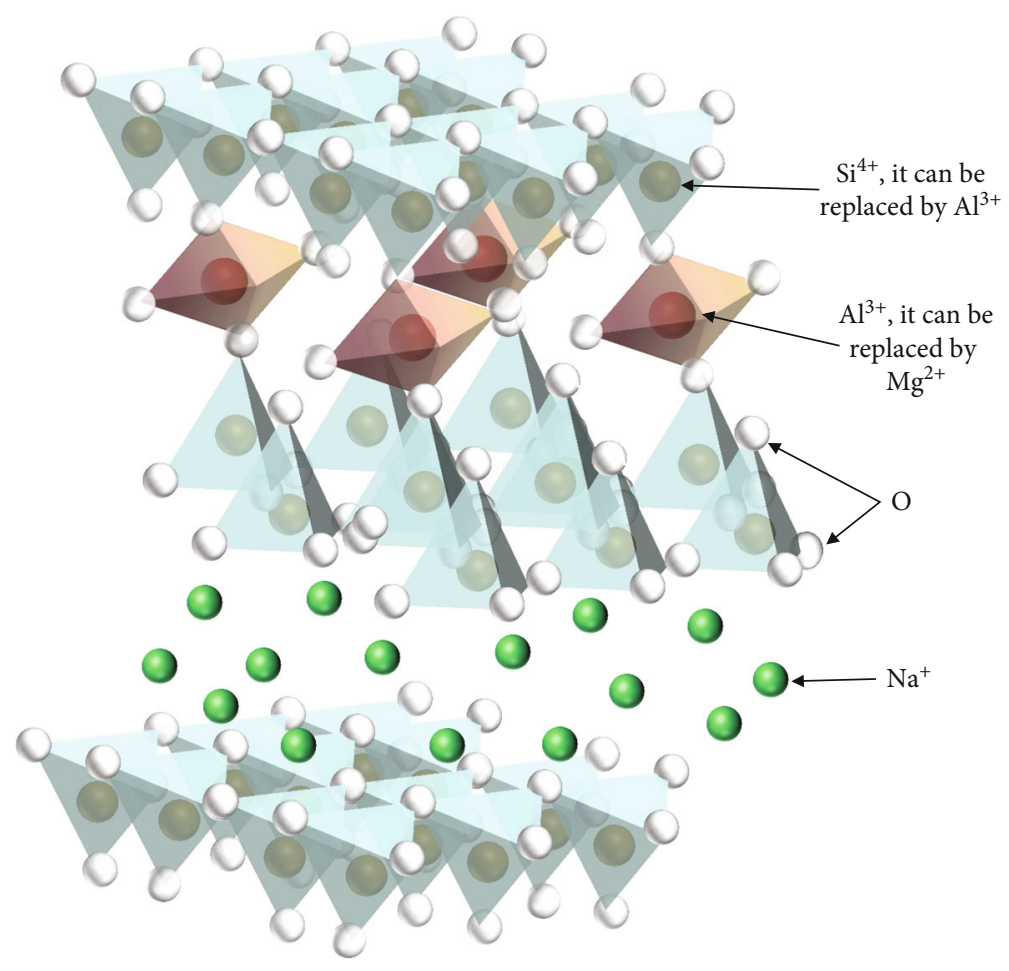

FIgURE 2: Schematic diagram of the montmorillonite crystal structure.

embedded in the interlayer domain structure of MMT through molecular intercalation to achieve mechanical interlocking between the filler and the matrix; (2) by destroying the interlayer structure of MMT, it promotes the exfoliation of the lamellae to form graphene-like nanosheets, thereby achieving the enhancement of the mechanical properties of the polymer matrix through the nanoreinforcing effect.

3.1. Molecular Chain Intercalation Strengthening. It is well known that the interlayer domain of MMT has a swelling effect. In a liquid environment or in a molten state, its interlayer domain expands and increases, making polymer molecular chains easy to achieve intercalation behavior, as shown in Figure 3. In detail, in the mixed solution of MMT and polymer, MMT absorbs water to cause the expansion effect of the interlayer domain, so that the polymer molecular chain is successfully embedded in the MMT interlayer domain, while the other end of the molecular chain is miscible with the polymer matrix. In short, under the synergistic effect of covalent or noncovalent intermolecular 
TABLE 1: Montmorillonite enhances polymer mechanical properties.

\begin{tabular}{|c|c|c|c|}
\hline $\begin{array}{l}\text { MMT } \\
\text { content } \\
\text { (wt } \%)\end{array}$ & Polymer matrix & Mechanical performance enhancement results & References \\
\hline 0.2 & $\begin{array}{l}\text { Polytetrafluoroethylene/ } \\
\text { glass fiber }\end{array}$ & $\begin{array}{l}\text { Tensile strength achieved } 23.1 \mathrm{MPa} \text {, increased by } 41 \% \text { and young's modulus achieved } \\
165 \mathrm{MPa} \text {, increased by } 14 \%\end{array}$ & [43] \\
\hline \multirow[t]{2}{*}{2.0} & Poly (lactic acid) & $\begin{array}{l}\text { Elastic modulus achieved } 4.3 \mathrm{GPa} \text {, increased by } 34 \% \text {. Tensile strength achieved } \\
\qquad 75.6 \mathrm{MPa} \text {, increased by } 1.9 \%\end{array}$ & [38] \\
\hline & Bacterial cellulose & Tensile strength was increased up to $210 \mathrm{MPa}$ from $151.3 \mathrm{MPa}$ & {$[44]$} \\
\hline 3.0 & $\begin{array}{l}\text { Poly (vinyl alcohol)/ } \\
\text { chitosan }\end{array}$ & Tensile modulus and tensile strength increased by $35 \%$ and $33 \%$, respectively & {$[45]$} \\
\hline 4.0 & Bacterial cellulose & Young's modulus was increased up to $5.7 \mathrm{GPa}$ from $4.2 \mathrm{GPa}$ & {$[44]$} \\
\hline 4.5 & Poly-l-lactic acid & Tensile strength and modulus increased by $44.1 \%$ and $66.9 \%$, respectively & {$[46]$} \\
\hline 5.0 & Poly ( $\varepsilon$-caprolactone) & Tensile strength and compressive strength increased by $83 \%$ and $78 \%$, respectively & [47] \\
\hline \multirow{2}{*}{10} & $\begin{array}{l}\text { Chitosan/ } \\
\text { hydroxyapatite }\end{array}$ & Elastic modulus increased by $36 \%$ & [48] \\
\hline & Chitosan-gelatin & $\begin{array}{c}\text { Young's modulus was increased up to } 20.18 \mathrm{MPa} \text { from } 17.245 \mathrm{MPa} \text {. Compressive } \\
\text { strength was increased up to } 21.6 \mathrm{MPa} \text { from } 4.48 \mathrm{MPa}\end{array}$ & [49] \\
\hline
\end{tabular}

interactions and the mutual compatibility of organic materials, intercalated molecular chains are expected to build the link between MMT and polymers. As a result, a molecular cross-linking bridge is built between inorganic and organic substances; that is, an interlocking structure is formed in the composite material. The existence of this interlocking structure can significantly hinder the movement of polymer chains when the composite material system is subjected to external forces, thereby increasing the interaction between the polymer and MMT. In addition, the embedding of molecular chains increases the space between the MMT layers to a certain extent, that is, increases the contact area between the MMT nanofiller and the polymer matrix. In the composite material system, the formation of interlocking structure increases the molecular force between the two phases, and the expansion of the contact area between the two phases increases the number of interlocking structures in the system. Under this synergistic effect, it is expected to significantly improve the mechanical properties of composite materials. In other words, using MMT as the nanofiller phase is expected to achieve significant effects in enhancing the mechanical properties of polymer bone scaffolds.

The use of MMT as nanofiller to enhance the mechanical properties of polymer matrix has been widely accepted. Mauro et al. [52] added 1\%, 3\%, and $10 \mathrm{wt} \%$ MMT to hydrogels based on peptidomimetic polyamidoamine. When the degree of crosslinking of the hydrogel was constant, the shear storage modulus improved as the increase of MMT content. The shear storage modulus of hydrogel with MMT content of $10 \mathrm{wt} \%$ reached $200 \mathrm{KPa}$, which was 20 times higher than the original hydrogel. It might be attributed to the double action of the electrostatic force and the increase in contact area. This dual effect makes the hydrogel and MMT complete the intercalation structure, forming a complex and interconnected network. Paluszkiewicz et al. [53] prepared composite materials by adding $5 \mathrm{wt} \%$ MMT to chitosan (CS) solution in an acidic environment. FTIR results showed that the $\mathrm{Si}-\mathrm{O}-\mathrm{Si}$ group of MMT formed hydrogen bonds with the hydroxyl and amino groups of CS. This strong interfacial interaction promotes the effective transfer of interfacial stress. Therefore, compared with pure $\mathrm{CS}$, the tensile strength of CS-MMT is increased by about 10-12 MPa, and the Young's modulus is increased by $20 \%$. A recent study [48] found that when the content of MMT was less than $4.5 \mathrm{wt} \%$, the tensile strength of the PLLA/ MMT composite scaffold increased with the increase of the content; the highest increase was $44.1 \%$ (reach $26.8 \mathrm{MPa}$ ). However, as the content of MMT continues to increase, the growth trend of the mechanical properties of the composite scaffold begins to reverse, resulting in a decrease in the mechanical properties. Meanwhile, the author further studied the cross-sectional morphology of the composite material to explore the mechanism of the incorporation of MMT to enhance the mechanical properties of the composite material and found that the PLLA/MMT scaffold has many folds and torn ligaments on the fracture surface compared to the pure PLLA scaffold. These studies showed that, as a nanofiller phase, MMT exhibited an amazing effect in enhancing the mechanical properties of a single polymer matrix.

In addition, some studies have explored the influence of MMT as an incorporation on the mechanical properties of polymer composites. Bee et al. [54] added MMT to a composite matrix of polylactic acid (PLA) and naturally derived hydroxyapatite (HAp) in the molten state to form a ternary composite material, focusing on the mechanical properties of the composite material. They found that when the MMT content was $2 \%$, the increase in tensile strength was most significant and believed that the improvement in the tensile properties of the composite material was mainly due to the following aspects: Firstly, the increase in the interfacial tension between PLA and HAp promoted PLA intercalation of molecules in the interlayer domain of MMT. Secondly, MMT nanoparticles restricted the migration of PLA molecules through their interlayer domains, thereby 


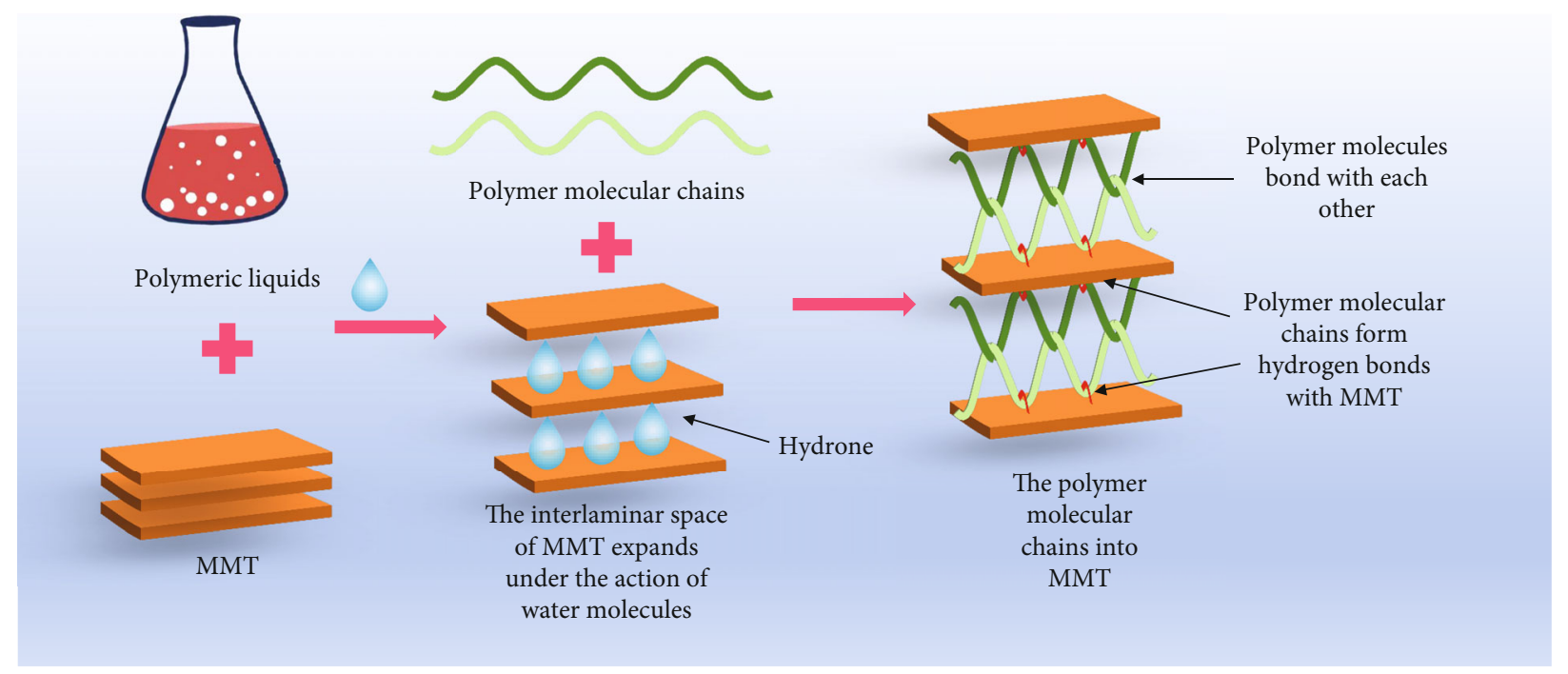

FIGURE 3: Schematic diagram of polymer molecular chain intercalate into MMT.

enhancing the PLA matrix. Thirdly, mutual repulsion at the interface between $\mathrm{PO}_{4}{ }^{3-}$ of nonpolar HAp and the polar site of MMT promoted the dispersion of MMT, thereby further releasing the potential of nanostrengthening effect.

Olad et al. [51] studied the synergistic effect of graphene oxide (GO) and MMT on the performance of chitosangelatin (CS-Gel) scaffolds. XRD results showed that the characteristic peak of montmorillonite was located at $2 \theta=$ $7.48^{\circ}$, while the characteristic peaks of MMT in CS-Gel/ MMT and CS-Gel/GO/MMT were located at $2 \theta=4.98^{\circ}$ and $2 \theta=4.78^{\circ}$, which proved that the polymer chain was inserted into the MMT interlayer domain. Compared with the CS-Gel scaffold, the mechanical properties of the CSGel/GO/MMT scaffold were significantly improved. Concretely, the Young's modulus was increased from 17.56 MPa to $22.73 \mathrm{MPa}$, and the compressive strength was increased from $0.14 \mathrm{MPa}$ to $0.2265 \mathrm{MPa}$. The author believed that this benefit from the ability of GO and MMT to improve the mechanical stability of the scaffold. Among them, GO has a significantly larger surface area and abundant oxygen-containing functional groups, which provided more landing sites for the attachment of polymer chains. It was similar to the reports of other researchers such as Ionita et al. [55]. The interlayer domain structure of MMT is conducive to the intercalation of polymer molecular chains, which provide a higher degree of geometric constraints for the mobility of polymer chains.

As we all know, the pore shape, pore size, and porosity of the scaffold are important factors that affect its mechanical properties [56, 57]. Generally, the pore size and porosity have a negative correlation with the mechanical properties. That is, the larger the pore size and porosity, the worse the mechanical properties of the scaffold. Regarding the influence of the pore shape on the mechanical properties, researchers mainly design the pore shape of the bracket from the perspective of bionics to obtain more excellent mechanical properties. In the process of polymer molecular chain intercalation with MMT, in addition to the abovementioned increase in contact area and mechanical interlocking function, the thickness of the pore wall of the matrix can also be increased, and even the uniformly dispersed MMT can also obtain a uniformly distributed pore size. These behaviors are expected to further contribute to the improvement of the mechanical performance of the scaffold. Zheng et al. $[58,59]$ have done a lot of research on the enhancement of mechanical properties of gelatin and chitosan intercalated MMT. It was found that after adding MMT, the pore wall of the scaffold became thicker, and the tensile strength and Young's modulus increased. Unfortunately, as the content of MMT continues to increase, the pore morphology becomes irregular, and Young's modulus and tensile strength decrease instead. Lee et al. [60] added 5.79vol\% MMT to the poly-L-lactic acid (PLLA) solution and then fabricated a double-pore scaffold structure through cold compression molding and electrospinning. During the biodegradation process, the developed nanocomposite fiber scaffold exhibited significantly better strength and structural integrity than the original PLLA one. Ali et al. [61] studied the effect of MMT (1-5\%) concentration on the performance of chitosan/xylan $(1: 1)$ bone scaffolds. The results showed that when the content of MMT was less than $3 \mathrm{wt} \%$, the porosity of composite scaffold increases with the increased content. XRD results indicated that it may be attributed to the intercalation of polymer chains into the interlayer domain of MMT. In addition, the composite scaffold with $5 \mathrm{wt} \%$ MMT can produce needle-like apatite in simulated body fluid, which further improves the scaffold's mechanical properties, as well as the biological activity.

3.2. Strengthening and Toughening of MMT Nanosheets. MMT is a layered minerals composed of extremely finegrained hydrous aluminosilicates. $\mathrm{H}_{2} \mathrm{O}$ molecules and exchangeable cations are linked by weak hydrogen bonds to form a hydrated state and exist in the interlayer space. The number of water molecular layers is related to the cation valence, up to four layers. Studies have showed that under 
the action of high-energy ball milling, the impact and friction of the grinding balls will disrupt the molecular interaction between the layers, thereby destroying the stability of the MMT layered structure. It will cause the exfoliation of the single-layer MMT crystals, thereby obtaining graphenelike MMT nanosheets with a large specific surface area [62], as shown in Figure 4(a). As the ball milling progresses, the exfoliation effect of MMT becomes more obvious, and finally, complete exfoliation is realized, which leads to the disordered structure of MMT. Although the ball milling method can obtain MMT nanosheets, it is worth noting that it takes a long time to exfoliation of the MMT, and the final product faces the risk of contamination.

In order to overcome the abovementioned problems, some new technologies have been studied, especially ultrasound-assisted methods, as shown in Figure 4(a). Generally speaking, the exfoliation of MMT usually occurs in a liquid medium and is achieved under the assistance of mechanical stirring and ultrasound $[63,64]$. In particular, the high-frequency vibration energy provided by ultrasound makes the solution in the action area quickly form highenergy microjets, and the energy generated is much greater than the molecular force between MMT layers, so as to disrupt the connection between MMT layers and realize exfoliating to obtain MMT nanosheets $[65,66]$.

The obtained graphene-like MMT nanosheets not only have a higher aspect ratio and surface area but are more easily entangled with polymer chains to significantly increase the contact area, thereby strengthening the mechanical properties of the polymer matrix [67], as shown in Figure 4(b). Scholars [68] have studied the properties of polyvinyl alcohol (PVA)/MMT nanocomposites synthesized in aqueous solutions. It was found that when the content of montmorillonite is $4 \mathrm{wt} \%$, the Young's modulus of nanocomposites was increased by 2.5-3 times, compared with pure PVA. Their explanation for the sharp increase in the Young's modulus of the polymer matrix includes the fact that MMT exfoliation produces a high aspect ratio and a large contact area with the polymer. Kosalczyk et al. [69] proved that the addition of exfoliated MMT nanosheets to polymer significantly increased the flexural modulus and strength. In addition, the exfoliated MMT nanosheets also help to improve the tensile strength and Young's modulus of the polymer by restricting the movement of the polymer chains around it [70, 71]. Habibi et al. [72] added MMT to chitosan/gelatin composites. MMT functions as a compatibilizer, reducing the interfacial tension of chitosan and gelatin, and enhancing compatibility. Generally, an increase in the interfacial tension of a polymer will result in a decrease in mechanical properties $[73,74]$. Therefore, the exfoliated MMT nanosheets significantly enhance the interfacial interaction to reduce the interfacial tension, which might be the essential reason for the enhanced tensile strength of the polymer composites containing MMT.

The crack evolution process of composites contains a variety of toughening mechanisms, including crack deflection, interface delamination, crack bridging, and interface friction [75], as shown in Figure 4. The maximum stress of the initial polymer is concentrated at the crack tip, and when the exfoliated MMT is evenly distributed in the polymer matrix, it can not only increase the friction between the interface and increase the energy required for fracture but also limit the crack propagation; Secondly, it allows the main crack to change the trajectory of the expansion and extension, ensuring that it is difficult for the crack to penetrate the entire polymer matrix, as shown in Figure 4(c)-3. In addition, the exfoliated MMT nanosheets can bridge the crack branches, allowing them to form a closing force to achieve toughness, as shown in Figure 4(c)-4. Simply put, the exfoliated MMT nanosheets can carry a large number of external forces, reduce the stress concentration of cracks, and effectively improve the fracture toughness of the polymer matrix. For example, Jiang et al. [76] prepared PLA nanocomposites by direct melt extrusion. The results showed that the strength, modulus, and elongation at break of the obtained nanocomposites containing $2.5 \mathrm{wt} \% \mathrm{MMT}$ were increased by $2 \%, 14 \%$, and $288 \%$, respectively, compared with pure PLA.

Although the mechanical properties of the polymer matrix are enhanced by the interlocking of polymer chains and the exfoliating of MMT, but unembedded, unpeeled, excessive MMT will form aggregation in the polymer, causing stress concentration and formation of fracture strain, leading to failure [77, 78]. Recently, members of Zhang et al.'s [79] research team prepared polypropylene (PP)/ MMT nanocomposites. When MMT content reached to $3 \mathrm{wt} \%$, the tensile strength of polymer matrix was increased from 42.3 MPa to 49.6 MPa. However, when MMT content was exceeded $3 \mathrm{wt} \%$, the tensile strength decreases instead. It is because the excessive MMT is unevenly distributed in the polymer matrix, leading to the formation of agglomeration. The agglomerated MMT particles were weak spots and the entry point for crack development and expansion, which ultimately reduced the mechanical properties of the polymer-MMT composites. Nawang et al. [80] studied the addition of montmorillonite to nanohydroxyapatite nanocomposites, and the results showed that the addition of $10 \%$ MMT increased the flexural strength and compressive strength of the composite by $18.9 \%$ and $107.9 \%$, respectively. But 20\% MMT increased the flexural strength and compressive strength of the composite by only $17.1 \%$ and $63.1 \%$. This means that $20 \%$ of MMT has a stress concentration in the matrix. When the stress applied by these stressconcentrated parts exceeds a certain limit, cracks will occur, and the cracks will spontaneously propagate, leading to material failure. Therefore, compatibility of the MMT nanolayer with the polymer should be improved, and the montmorillonite is usually treated with organic modification.

\section{Organic Modification of Montmorillonite}

Polymer/montmorillonite is the most promising type of nanocomposite among many inorganic nanoparticles modified composites. Due to the unique layered one-dimensional nanostructure characteristics and morphological characteristics of montmorillonite, its interlayer space has designable reactivity, a large specific surface area (up to $750 \mathrm{~m}^{2} / \mathrm{g}$ ), and a diameter/thickness ratio of more than 200. This 


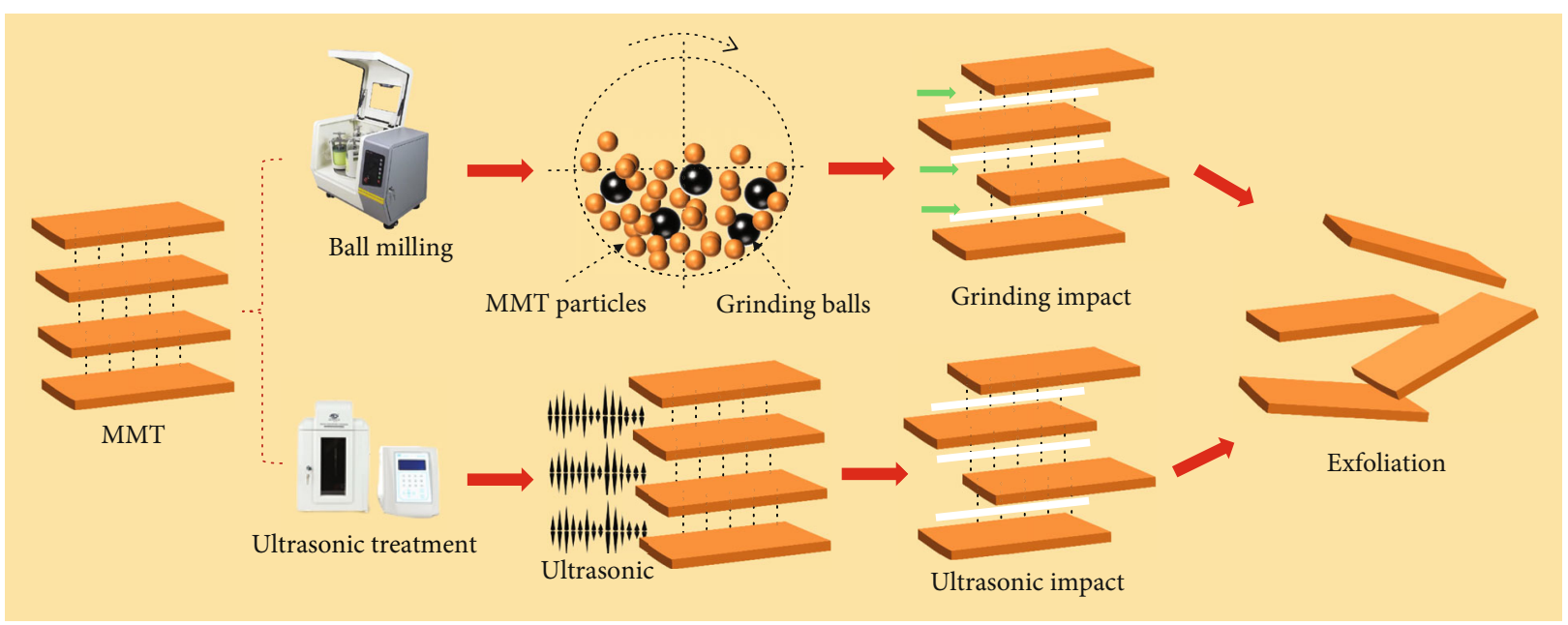

(a)

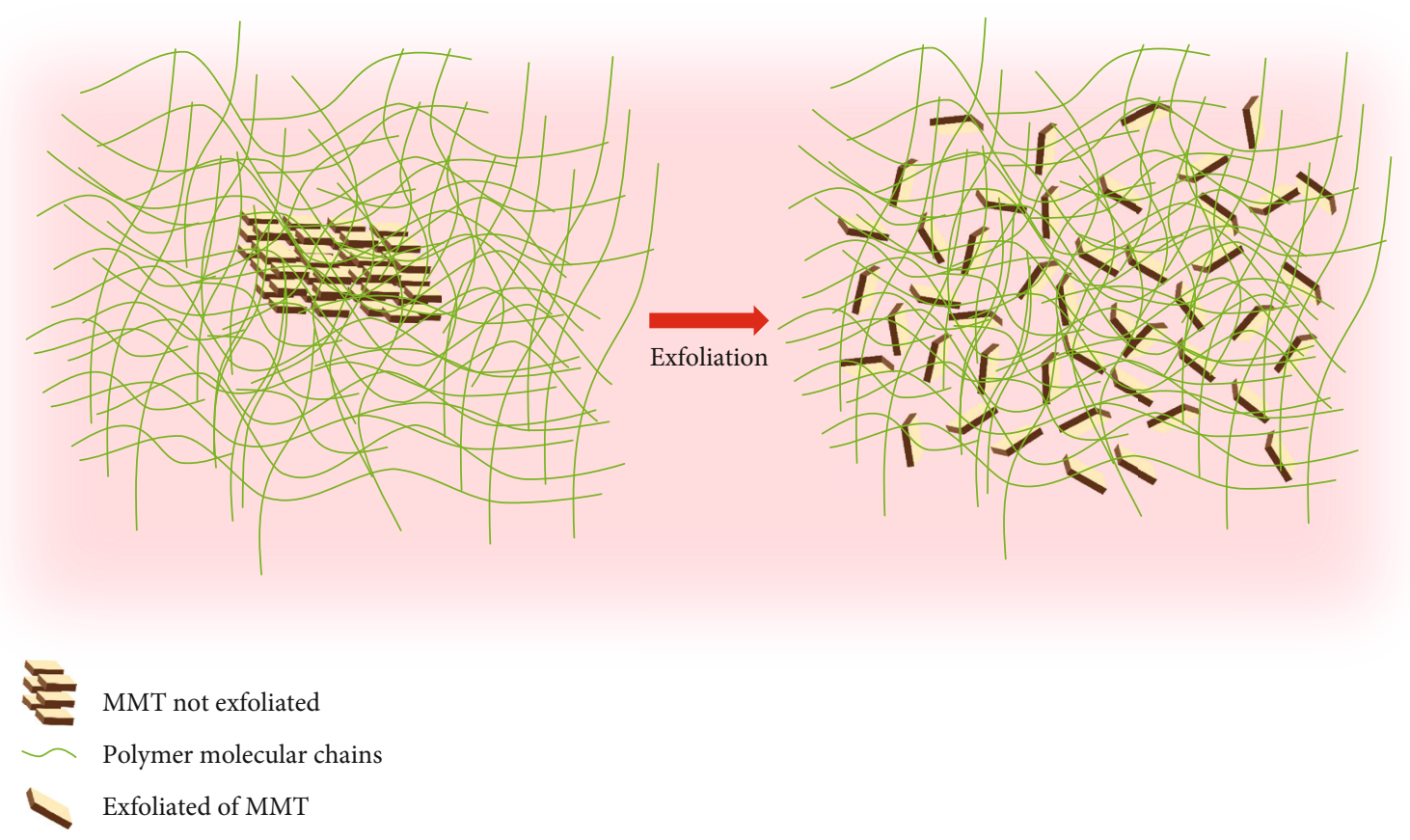

(b)

FIgURE 4: Continued. 

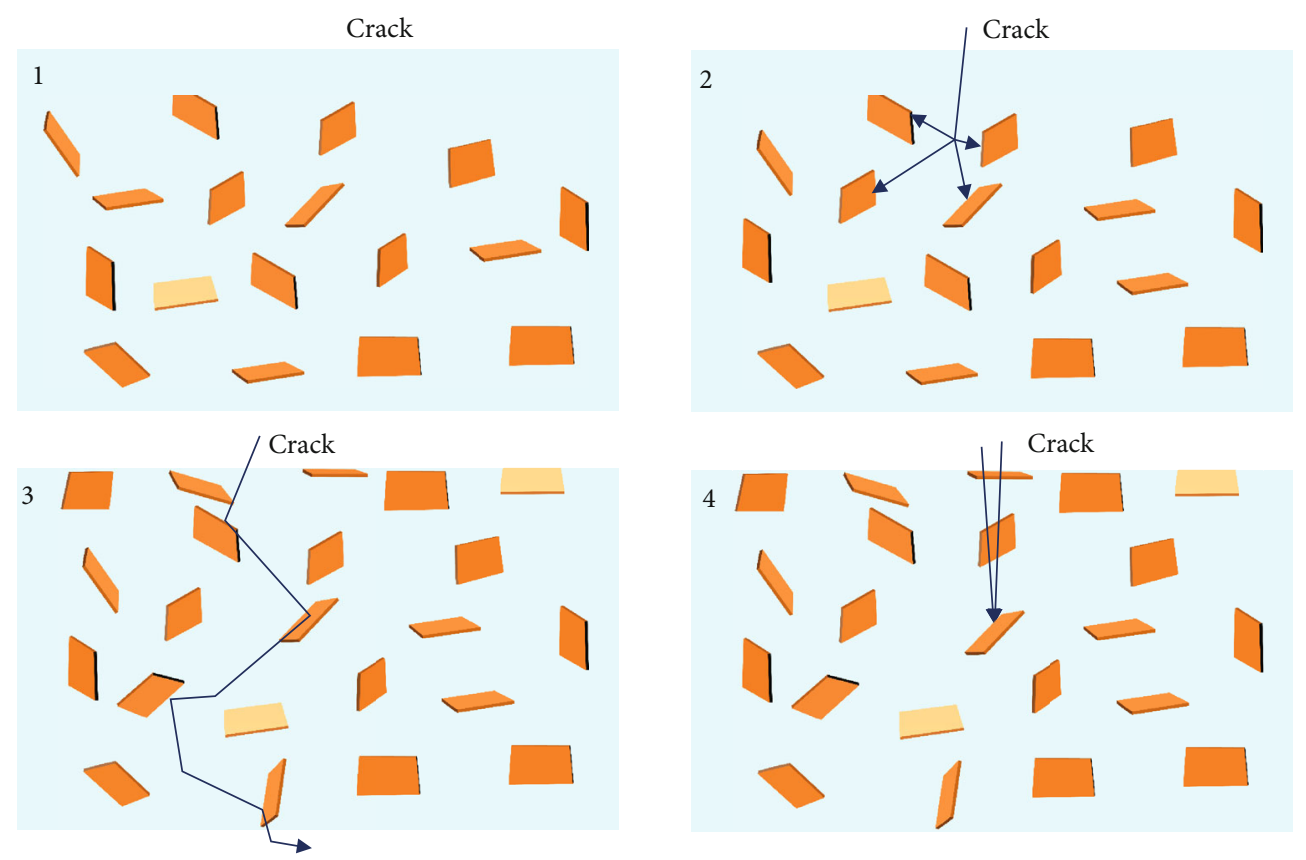

MMT nanosheet

Polymer matrix

(c)

FIGURE 4: The formation of MMT nanosheets and the mechanism of strengthening polymer composites: (a) the exfoliation mechanism of MMT; (b) the mechanism of strengthening polymer materials by MMT nanosheets; (c) the crack strengthening and toughening mechanism of polymer/MMT composites.

nanostructure and morphological characteristics endow polymer materials with excellent mechanical properties, thermal properties, functional properties, and other physical properties. However, since MMT and polymer are inorganic and organic, respectively, the inherent differences in physical and chemical properties between them are likely to lead to poor compatibility, and defects such as uneven dispersion, aggregation, and stress concentration are likely to occur in composites. The existence of these defects weakens the effect of MMT nanofillers in enhancing the mechanical properties of the polymers. Recently, one of the effective methods to improve interface compatibility and promote uniform dispersion of fillers was organic modification. As shown in Table 2, modified MMT to improve the mechanical properties of polymers has been favored by many scholars, and the effect can be seen. The methods of organic modification of MMT mainly include surface graft modification and cation exchange modification. This section summarized the latest progress on organically modified MMT.

4.1. Surface Graft Modification of MMT. Surface graft modification refers to the chemical reaction between nanoparticle surface functional groups and modifier molecules. Due to the covalent combination of organic and inorganic functional groups in the surface graft modification, it can not only change the surface structure and properties of nanoparticles but also make them have higher chemical stability [81]. Grafting is a feasible way to covalently immobilize organic functional groups on the surface of montmorillonite. During the grafting process, the surface hydroxyl groups of MMT provide a large number of anchor points for organic functionalization.

The surface of MMT has a large number of hydroxyl groups, which is inherently hydrophilic, and has a weak affinity with most hydrophobic substrates [91]. However, surface-grafted modified MMT can better enhance the affinity between functional groups. Therefore, surface modification has become an important method to adjust material properties [92]. Grafting modification can occur on the outer surface of MMT without changing the basal plane spacing or on its interlayer space or "broken" edge, thereby expanding its interlayer space spacing [93-95]. Zulfiqar et al. [96] used aminobenzoic acid to modify MMT. They grafted amino $\left(-\mathrm{NH}_{2}\right)$ functional groups on the hydroxyl groups on the outer surface of MMT. The results showed that the distance between the layers of MMT did not change. However, in the study of $\mathrm{He}$ et al. [93], they used the grafting reaction of the silylation reagent 3aminopropyltriethoxysilane (APTES) with MMT. X-ray diffraction results showed that the interlayer spacing of MMT before grafting was $1.18 \mathrm{~nm}$, and the interlayer spacing after grafting increased to $1.77 \mathrm{~nm}$. Su et al. [97] also used APTES to silanize MMT. On the one hand, the interlayer spacing of montmorillonite increased up to $2.09 \mathrm{~nm}$ from $1.48 \mathrm{~nm}$ during silanization, as shown in Figure 5. At the same time, the modifiers react with each other to generate a siloxane bond, 
TABLE 2: Mechanical properties of polymers increased by modified MMT.

\begin{tabular}{|c|c|c|c|c|}
\hline $\begin{array}{l}\text { MMT } \\
\text { content } \\
(\mathrm{wt} \%)\end{array}$ & Polymer matrix & Organic modifier & Mechanical performance enhancement results & References \\
\hline 0.4 & $\begin{array}{l}\text { Polytetrafluoroethylene/ } \\
\text { glass fiber }\end{array}$ & $\begin{array}{l}\text { Quaternary ammonium } \\
\text { compounds }\end{array}$ & $\begin{array}{l}\text { Tensile strength achieved } 25.5 \mathrm{MPa} \text {, increased by } \\
48 \%\end{array}$ & {$[43]$} \\
\hline \multirow{4}{*}{1.0} & & $\begin{array}{l}\text { Dimethyl dihydrogenated tallow } \\
\text { ammonium }\end{array}$ & Modulus increased by $76 \%$ & \multirow{2}{*}[80]{} \\
\hline & Poly methyl methacrylate & $\begin{array}{l}\text { Methyl tallow bis-hydroxyethyl } \\
\text { quaternary ammonium }\end{array}$ & $\begin{array}{l}\text { Modulus increased by } 82 \% \text { and toughness } \\
\text { achieved } 1256 \mathrm{~J} / \mathrm{m}^{3}\end{array}$ & \\
\hline & $\begin{array}{l}\operatorname{Poly}(\varepsilon \text {-caprolactone }) / \text { poly } \\
\text { (lactic acid) }\end{array}$ & $\begin{array}{l}\text { Methyl, bis-hydroxyethyl, and } \\
\text { octadecyl ammonium }\end{array}$ & $\begin{array}{c}\text { Tensile strength and elongation at break increased } \\
\text { by } 48 \% \text { and } 78 \% \text {, respectively }\end{array}$ & {$[81]$} \\
\hline & $\begin{array}{c}\text { Polyethylene/polybutene- } \\
1\end{array}$ & $\begin{array}{c}\text { Dimethyl dehydrogenated } \\
\text { tallow }\end{array}$ & $\begin{array}{l}\text { Organoclay reduced the interparticle distance and } \\
\text { enhanced interface interaction }\end{array}$ & {$[82]$} \\
\hline \multirow{3}{*}{5.0} & Poly (ester amide) & $\begin{array}{l}\text { Organo-polyaniline nanofibrous } \\
\text { chains }\end{array}$ & $\begin{array}{l}\text { Tensile strength achieved } 14.3 \mathrm{MPa} \text {, increased by } \\
\qquad 98 \%\end{array}$ & {$[83]$} \\
\hline & $\begin{array}{l}\text { Poly }(\varepsilon \text {-caprolactone }) / \\
\text { cellulose acetate butyrate }\end{array}$ & $\begin{array}{l}\text { Methyl dihydroxyl ethyl } \\
\text { hydrogenated tallow } \\
\text { ammonium }\end{array}$ & $\begin{array}{l}\text { Tensile modulus achieved } 471 \mathrm{MPa} \text {, increased by } \\
\qquad 37 \%\end{array}$ & {$[84]$} \\
\hline & $\begin{array}{l}\text { Poly (hydroxybutyrate- } \\
\text { co-hydroxyvalerate) }\end{array}$ & Cloisite-30B & $\begin{array}{c}\text { Young's modulus achieved } 7.1 \pm 1.9 \mathrm{MPa} \text {, } \\
\text { increased by } 103 \%\end{array}$ & [85] \\
\hline \multirow{4}{*}{10} & $\begin{array}{l}\text { Chitosan/ } \\
\text { polygalacturonic acid }\end{array}$ & Amino valeric acid & Compressive modulus increased by $400 \%$ & {$[86]$} \\
\hline & Poly (lactic acid) & Cloisite-30B & $\begin{array}{l}\text { Young's modulus was increased up to } \\
5140( \pm 210) \mathrm{MPa} \text { from } 3800( \pm 130) \mathrm{MPa}\end{array}$ & {$[87]$} \\
\hline & $\operatorname{Poly}(\varepsilon$-caprolactone $)$ & (3-aminopropyl) triethoxysilane & Tensile strength increased 3.46 times & {$[47]$} \\
\hline & Poly(ether ether ketone) & $\begin{array}{l}\text { Octadecyltrimethyl ammonium } \\
\text { chloride }\end{array}$ & $\begin{array}{l}\text { Flexural strength achieved } 200 \mathrm{MPa} \text {. Yield } \\
\text { strength achieved } 105 \mathrm{MPa} \text {, increased by } 10.5 \%\end{array}$ & {$[88]$} \\
\hline
\end{tabular}

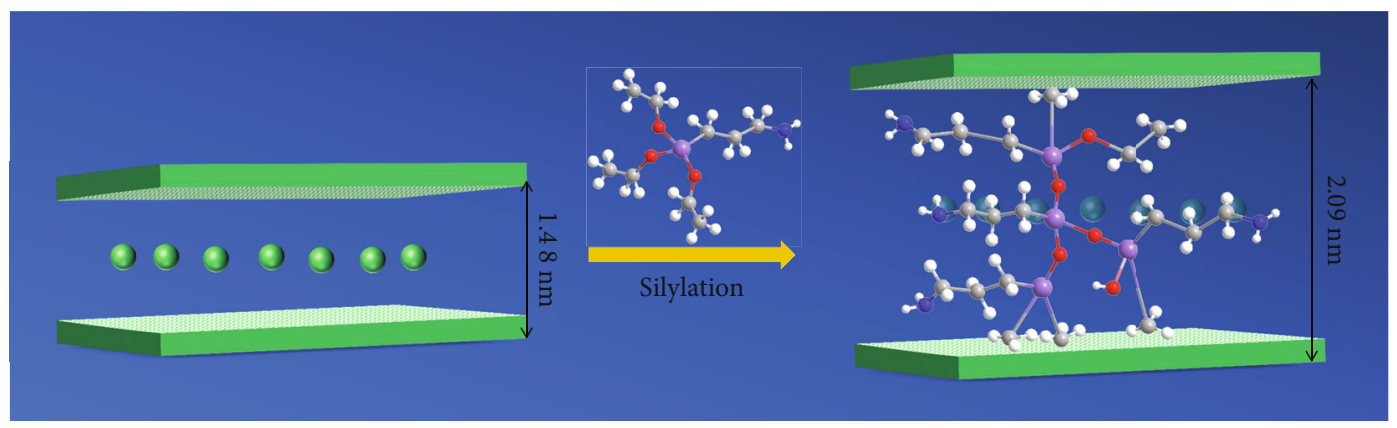

FIGURE 5: Schematic diagram of the effect of APTES silanization on the interlayer space of montmorillonite.

which causes an interlocking effect between the layers. This interlayer locking fixes the height of the MMT interlayer space, which is more convenient for the polymer to perform intercalation behavior. Besides, graft modification of MMT is also affected by factors such as the type of modifier and solvent and the degree of modification. For example, cetyltrimethylammonium modified MMT has poor dispersibility in alcohol with shorter carbon chains; on the contrary, it has better dispersibility in alcohol with longer carbon chains [98].

The surface modification of MMT has been proven to be an effective method to enhance the compatibility and uniform dispersion of nanofillers with polymers. Yang et al. [44] modified MMT (QACMMT) with quaternary ammo- nium compounds and used it to reinforce polytetrafluoroethylene/glass fiber (PTFE/GF) composites. They evaluated the dispersibility and dispersion stability of MMT and QACMMT in water. The results showed that pure MMT still aggregated after standing for 60 minutes. By comparison, QACMMT appears as more uniformly dispersed particles in the aqueous solution without stratification, indicating stable quality and good dispersion in water. In addition, QACMMT modified composites exhibit the highest tensile strength, modulus, fracture strain, and toughness. This is attributed to the good dispersibility of QACMMT in the polymer matrix, while enhancing the interface compatibility between glass fiber and polytetrafluoroethylene. Zhu et al. [83] studied the effects of surface-modified montmorillonite 


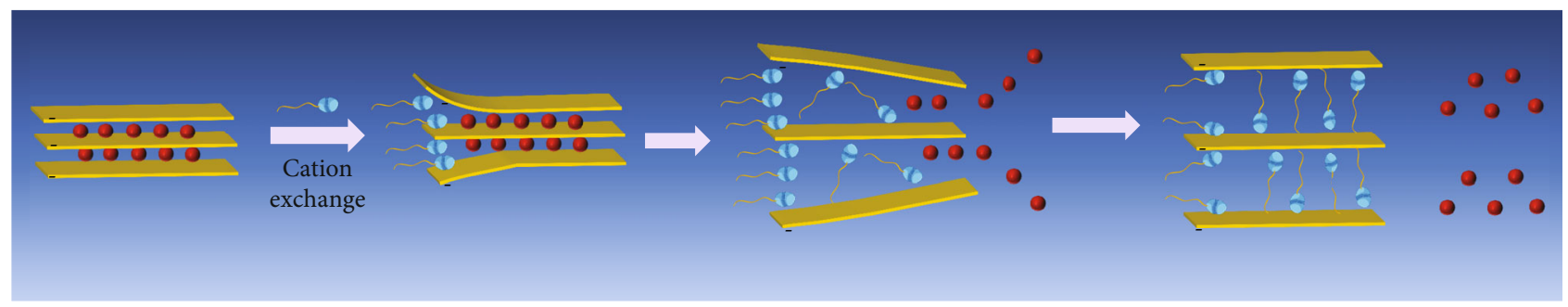

$\mathrm{Na}^{+}$
Organic cations

Figure 6: Schematic diagram of cation exchange of MMT.

on the microphase dispersion and interfacial interaction in polycaprolactone PCL/polylactic acid PLA composites. The results showed that the modified montmorillonite not only significantly increased PCL/PLA interface interaction but also significantly improved the uniform dispersion of PLA. Meanwhile, the results also showed that the obtained PCL/ PLA/MMT nanocomposite can be well balanced among Young's modulus, tensile strength, and elongation. The reason was that the addition of MMT increases the interface interaction and more uniform phase dispersion, so that the polymer deforms simultaneously under stretching and has a higher elongation and tensile strength. Khosravi and Eslami-Farsani [99] used 3-glycidylpropyltrimethoxysilane (3-GPTS) to modify the mechanical properties of nanomontmorillonite (Na-MMT) on unidirectional basalt fiber (UDBF)/epoxy resin composites. The results showed that after adding $5 \mathrm{wt} \%$ of 3-GPTS/MMT, the flexural strength, tensile strength, and compressive strength increased by $28 \%, 11 \%$, and $35 \%$, respectively. The results showed that the adhesion between the modified MMT-enhanced composite samples was improved.

Recently, the modification of polymers by incorporating two nanofillers at the same time has received great attention, and the existence of synergistic effects has been demonstrated [100-102]. For example, the combination of carbon nanotubes (CNT) and MMT has been successfully used to improve the mechanical properties of polymers, where CNTs are selectively distributed in the polymer matrix, while organic MMTs are distributed at the interface junction [103]. Zhu et al. [104] studied the modified MMT and carbon nanotubes (CNT) to synergistically improve the strength and toughness of the polymer. The modulus, tensile strength, and toughness of the polymer matrix had been greatly improved under the combined action of CNT and MMT. This was attributed to the good dispersion of the organically modified nanofillers; a large number of microcracks and an extremely stretched polymer matrix were generated during the stretching process, which dissipated a large amount of energy. Zhang et al. [105] prepared a CNT/MMT hybrid by growing CNT in situ on MMT. CNT/MMT hybrid material showed excellent reinforcement effect on polymer matrix such as nylon 6 [106].

The above research provided a solid theoretical basis and sufficient reference for the surface grafting modified MMT to optimize the performance of the polymer matrix. The unique molecular structure and high specific surface area of MMT are not only conducive to graft functionalization but also become the best filler for the target polymer matrix, thereby forming high-quality composite materials.

4.2. Cation Exchange Modification. As we all know, the cations (mainly $\mathrm{Na}^{+}$) in the interlayer space of MMT are only loosely immobilized by the negative charges on the surface, commonly known as hydrated cations. Therefore, the cations between the layers remain exchangeable, as shown in Figure 6. In addition, the electrostatic interaction between the negative charges on the inner surface of the MMT and the organic cations or the hydrogen bonds formed on the inner surface of the organic chains drive the exchange of cations in the interlayer space $[107,108]$. The cation exchange modification of MMT (OMMT) can occur in suspension, semisolid or solid state $[109,110]$. In particular, it was currently the preferred method to prepare cationic modified MMT in water suspension [111]. In the water dispersion, with the aid of mechanical stirring or ultrasound, organic cations can also be quickly introduced into the intermediate layer of MMT at room temperature. In addition, cationic modification of MMT can be assisted by microwaveassisted heating. For example, Peng et al. [112] prepared OMMT by a mixed suspension of dioctadecyl tetrahydroxyethyl dibromopropane diammonium and MMT in a microwave-assisted heating system. Luo et al. [113] modified MMT with butane-1,4-bis (dodecyldimethylammonium bromide) through the synergistic effect of microwave and ultrasound.

The cationic modification of montmorillonite is affected by the length of the organic cationic chain, the type of functional group, and the number of cations [79, 114, 115]. Cationic organic long carbon chain modifiers are more advantageous. Studies have clearly showed that when organic modifiers with longer carbon chains are inserted into the interlayer space of MMT, its intercalation/exfoliation was more likely to occur [116]. In contrast, organic modifiers with short chains (such as methacryloyl ethyl trimethyl ammonium chloride) are not closely arranged in the interlayer space of MMT, and do not effectively expand the interlayer space. MMT interlayer cation exchange capacity (CEC) can also affect its ion exchange performance [117, 118]. MMT with high CEC is generally easier to allow organic chains to enter the interlayer space and produce a 
TABle 3: Montmorillonite enhances polymer biocompatibility.

\begin{tabular}{lccc}
\hline $\begin{array}{l}\text { MMT } \\
\text { content }\end{array}$ & Polymer matrix & Biocompatibility enhancement results & References \\
\hline $1.5 \mathrm{wt} \%$ & Chitosan & Recruit native cells and promote calvarial healing & {$[37]$} \\
$3 \mathrm{wt} \%$ & PLLA/PGA & Promote MG-63 cell adhesion and proliferation & {$[131]$} \\
$5 \mathrm{wt} \%$ & Polyvinyl alcohol & Increased the water absorbency & {$[132]$} \\
$10 \mathrm{wt} \%$ & Poly(butylene adipate-co- & Showed good biological safety, noncytotoxicity, and high & {$[133]$} \\
$22.2 \mathrm{wt} \%$ & herephthalate) & hemocompatibility & {$[134]$} \\
$1.67 \mu \mathrm{g} / \mathrm{ml}$ & PLGA & Highly biocompatible and nontoxic & {$[135]$} \\
$10^{3} \mathrm{ppm}$ & Chitosan & Showed good biocompatibility and effectively stimulate cell proliferation & Promote proliferation of fibroblasts \\
$6 \mathrm{~g}$ & Chitosan & Promote gene expression & {$[136]$} \\
\hline
\end{tabular}

large interlayer spacing, thereby making it easier to form an intercalation/exfoliation structure. With the increase of chain length, chain number, and cationic modifier loading, the base spacing of MMT also increases [119-121]. For example, when the cation exchange capacity of MMT was 4.0CEC; substrate spacing for adding cetyltrimethylammonium bromide and octyltrimethylammonium chloride was $3.9 \mathrm{~nm}$ and $4.1 \mathrm{~nm}$ [122]. When the modifier added to MMT is 4.0CEC, the basic spacing formed by cationic modifiers with different alkyl chain numbers (octadecyl trimethylammonium bromide and dioctadecyldimethylammonium bromide) was $4.1 \mathrm{~nm}$ and $5.5 \mathrm{~nm}$, respectively. In addition, the alkyl chains of some organic cationic modifiers are arranged in parallel in the interlayer domain of MMT [123].

Changing types of cations between MMT layers are also an important way and method to improve its uniform dispersion in the polymer matrix. The cation exchange of MMT reduces its surface energy and at the same time reduces the interface energy between it and the polymerization, making it easier to achieve intercalation and exfoliation, resulting in a more uniform dispersion of MMT in the polymer matrix to enhance mechanical properties. Cationic modified clay minerals had been adopted by more and more researchers to improve the mechanical properties of the matrix. In the study of Hamidabadi et al. [124], chitosan-modified MMT was used to enhance the mechanical properties of PVA.

The results showed that the tensile properties, initial modulus, and toughness of the composite had been significantly improved. Shuai et al. [49] used (3-aminopropyl)triethoxysilane (KH550) to organically modify MMT to enhance polycaprolactone (PCL). The positively charged end of KH550 entered the interlayer of montmorillonite through cation exchange, and the end with long alkyl carbon chain extended in the opposite direction. With the extension of long chains, the interlayer spacing of montmorillonite increased, making the intercalation of PCL molecular chains more convenient. This kind of ion exchange with MMT can often produce new bonds (such as hydrogen bonds) to prevent the movement of polymer molecular chains, thereby enhancing the interface bonding ability. The mechanical performance test results show that the modified MMT can significantly enhance the tensile and compressive properties of the polymer matrix. It was also found that the dispersion ability of modified MMT was significantly higher than that of unmodified MMT in the PCL matrix.

In addition to improving the mechanical properties of polymer scaffolds, MMT is biocompatible and nontoxic in nature. Studies have shown that it can improve the ability of cell adhesion, migration, and proliferation on polymer scaffolds without causing positive immune responses and severe inflammatory reactions [125]. Relevant studies are summarized in Table 3. In general, MMT mainly affects the biocompatibility of scaffolds from the following aspects. Firstly, -OH, Si-O-Si, and other oxygen-containing groups of MMT can adjust the hydrophilicity of the surface of the scaffold to promote cell adhesion and growth. Secondly, the modified MMT can not only improve the hydrophobicity of scaffold surface but also can impart a positive charge to the surface scaffold, thereby further improving the biocompatibility of scaffolds. In addition, related studies have shown that modified MMT can not only enhance the mechanical properties of scaffolds but also improve its osteogenic properties [126, 127]. For example, Demir's [128] research team prepared a porous scaffold of Zn-doped PCL-MMT. The results showed that the in vitro proliferation and osteogenic differentiation of human adipose stem cells (hASCs) were improved. Kundu et al. [129] found that the addition of MMT significantly increased the alkaline phosphatase (ALP) expression of mesenchymal stem cells (MSCs). Kim et al. [130] studied the effect and mechanism of nano-MMT on the differentiation of osteoblasts and osteoclasts in vivo and in vitro. On the one hand, nano-MMT improves the activity of ALP and the expression of related genes in osteoblasts, thereby stimulates the proliferation and differentiation of osteoblasts. On the other hand, nano-MMT repressed the expression of receptor activator for cathepsin K, nuclear factor kappa-B ligand, and tartrate-resistant acid phosphatase, which hinders the growth and reproduction of osteoclasts.

Some researchers have used modified MMT to enhance the compatibility of two incompatible materials to enhance mechanical properties [138]. For example, in order to improve compatibility between PLLA and PGA, Yu et al. [131] modified composite materials by modifying MMT 


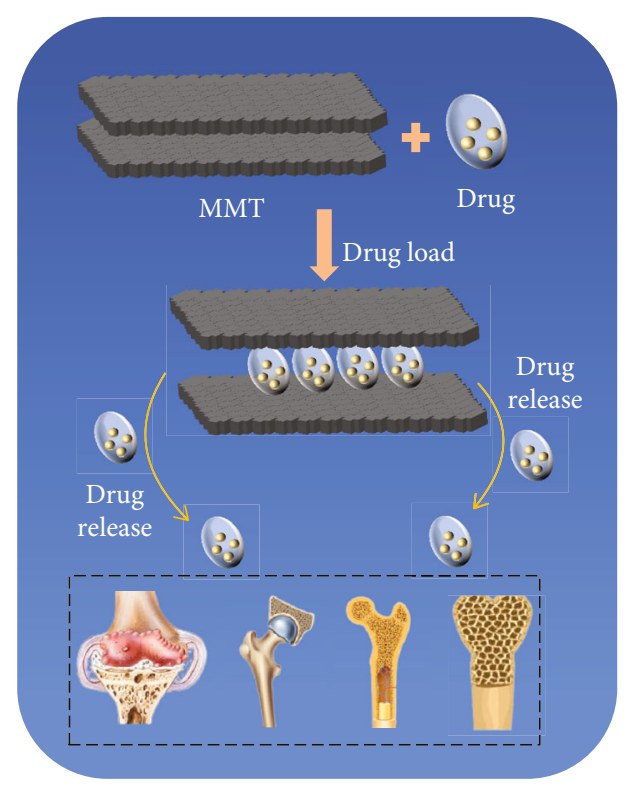

FIGURe 7: Drug loading/release of MMT.

with octedacy trimethyl ammonium chloride. It is worth noting that the $\mathrm{NH}_{2}$ group in the modified MMT not only formed a hydrogen bond with the $\mathrm{OH}$ group of PLLA but also formed a hydrogen bond with the $\mathrm{OH}$ group of PGA, and the three formed an interlocking structure. Therefore, through the effect of cationic modification of MMT, the compatibility of PLLA and PGA was improved. In terms of mechanical properties, the tensile performance of the PLLA/PGA stent with cationic modified MMT was nearly doubled compared with the composite stent without addition. Bozolan's research team [139] studied the effect of Lphenylalanine-modified montmorillonite on the mechanical properties of chitosan/carboxymethylcellulose/scleroglucan composite hydrogels. The results showed that the compressive stress values of hydrogel materials containing $0 \%, 1 \%$, $3 \%$, and $5 \%$ MMT were $126.45 \pm 8.83 \mathrm{kPa}, 152.31 \pm 2.72$ $\mathrm{kPa}, 210.94 \pm 2.36 \mathrm{kPa}$, and $266.99 \pm 6.60 \mathrm{kPa}$, respectively. The result was consistent with Liu [140] and Mohd's [141]. In bone tissue engineering, some metal cations can not only promote the activity and proliferation of osteoblasts but also have anti-inflammatory and antibacterial effects [142, 143]. For example, the replaced silver ion undergoes an oxidation-reduction reaction in MMT, and formed metallic silver had antibacterial properties [144-146]. This showed that the organically modified nanoclay has abundant functional group combination; therefore, MMT was often used as a carrier for drug loading and sustained drug release.

\section{Drug Loading-Release of MMT}

Common problems such as bacterial infections in bone tissue engineering greatly increase the risk of bone repair [147]. Drug delivery is one of the most important applications of organic functionalized montmorillonite. After proper modification, MMT has received more and more attention as a drug carrier and drug sustained release agent.
It can deliver drugs continuously, controllable and targeted, thereby improving its therapeutic effect.

The sustained release of drugs in montmorillonite usually requires drug molecules to be inserted into the interlayer space of montmorillonite, as shown in Figure 7. Otherwise, simple surface adsorption will result in a faster release rate. It may be attributed to the fact that the layered structure of MMT not only hinders the external erosion of drug but also inhibits the diffusion of drug from the interlayer domain to outside. Sadeghianmaryan et al. [148] studied a spinning scaffold made of polycaprolactone/montmorillonite nanocomposites loaded with curcumin (Cur). The results showed that by introducing MMT into the polymer matrix, the sudden release level was reduced, and PCL/20\% MMT had the lowest curcumin release. Silver nanoparticles are an effective antibacterial agent, with strong bactericidal activity and a wide range of bactericidal types and no bacteria resistance [149, 150]. However, Ag-based antibacterial materials face some problems. Ag nanoparticles are easy to aggregate in the polymer matrix and lead to rapid release of $\mathrm{Ag}^{+}$. Guo et al. [151] loaded $\mathrm{Ag}^{+}$into the interlayer space of MMT through ion exchange and was further chemically reduced to metal Ag with higher stability. When the MMT loaded with $\mathrm{Ag}$ was added to the PGA stent manufactured by 3D printing, the Ag exhibited uniform dispersion, and the composite scaffold exhibited antibacterial performance of sustained release of Ag.

In order to further evaluate the release mechanism of the drug in MMT, people usually fit the drug release data to the kinetic formula, such as Korsmeyer-Peppas model, Higuchi model, and zero-order and first-order, as shown in Table 4 [152, 153]. Among them, Higuchi model [154] (Equation (1)) and Korsmeyer-Peppas model [155] (Equation (2)) were the most commonly used in the research of MMT drug loading and release. According to the research of Panahi et al. [156] and Li et al. [157], under simulated gastric juice and simulated intestinal juice, the release kinetics of clarithromycin and dexibuprofen in MMT were confirmed to be consistent with the Higuchi model. In addition, some studies have concluded that the diffusion mechanism of drugs in MMT can be explained by the Korsmeyer-Peppas model. Among them, $0.45 \leq n$ corresponds to Fickian diffusion mechanism, $0.45<n<0.89$ corresponds to non-Fickian transport, $n=0.89$ corresponds to case II transport, and $n$ $>0.89$ corresponds to super case II transport $[158,159]$.

$$
f_{t}=Q=A \sqrt{D\left(2 C-C_{s}\right) C_{s} t}
$$

where $Q$ is the amount of drug released in time $t$ per unit area $A . C$ is the drug initial concentration. $C_{s}$ is the drug solubility in the matrix media, and $D$ is the diffusivity of the drug molecules (diffusion coefficient) in the matrix substance.

$$
\frac{M_{t}}{M_{\infty}}=K t^{n},
$$


TABLE 4: Kinetic models and mechanisms of montmorillonite release drugs.

\begin{tabular}{|c|c|c|c|}
\hline Drugs & Kinetic models & Diffusional release mechanisms & References \\
\hline 5-Fluorouracil & & Fickian diffusion & {$[164]$} \\
\hline Chlorpromazine & & Non-Fickian diffusion & [165] \\
\hline Hydrophobic ibuprofen & Korsmeyer-Peppas & Non-Fickian diffusion & [166] \\
\hline Sodium diclofenac & & Case II transport & [167] \\
\hline Ciprofloxacin & & Super case II transport & {$[168]$} \\
\hline Dexibuprofen & & Non-Fickian diffusion & [157] \\
\hline Tanshinone IIA & Higuchi & Non-Fickian diffusion & [169] \\
\hline Clarithromycin & & Fickian diffusion & [156] \\
\hline Sodium diclofenac & Zero-order & Super case II transport & {$[170]$} \\
\hline 5-Fluorouracil & First-order & - & {$[171]$} \\
\hline Curcumin & Power law & Non-Fickian diffusion & {$[148]$} \\
\hline Paracetamol Pa & Ritger-Peppas & Non-Fickian diffusion & [172] \\
\hline
\end{tabular}

where $M_{t} / M_{\infty}$ is a fraction of drug released at time $t . k$ is the release rate constant, and $n$ is the release exponent.

The release of drugs in MMT is mainly affected by the following factors. Firstly, when the drug-carrying system is exposed to the dissolving medium, the concentration gradient of the drug is the main driving force, which makes it exhibit explosive release behavior in the early period [160]. Secondly, the interlayer structure of MMT creates interconnected and tortuous barriers, which hinders the dissolution and diffusion of drug molecules and reduces the release rate of drugs [161]. Furthermore, there are intermolecular forces such as hydrogen bonds [156], covalent bonds [162], and ionic bonds [163] between drug molecules and MMT, which further hinder the release of drugs.

The sustained release of drugs in MMT depends on its content, the increase of interlayer spacing, and its dispersion in the matrix [160]. The research results of Bakre et al. [173] showed that in polycaprolactone/montmorillonite composite materials, as the concentration of MMT increases, the sustained release rate of curcumin slows down. The increased interlayer spacing after modification of MMT can optimize the sustained release performance. Yu et al. [174] used cetyltrimethylammonium bromide (CTAB) modified natural sodium montmorillonite (Na-MMT) as a carrier to carry the drug-amoxicillin (AMX) for tissue engineering. The results showed that the cumulative release rate of AMX with modified MMT at $75 \mathrm{~h}$ was only $45 \%$, while the cumulative release rate of AMX scaffold without modified MMT at $75 \mathrm{~h}$ reaches $80 \%$. Bounabi et al. [172] developed a drug delivery carrier for paracetamol, which was composed of a hydrogel composed of poly (2-hydroxyethyl methacrylate) and MMT. Among them, MMT was used as a polymer crosslinking agent, which prolongs the release time of paracetamol, delays the clearance of the drug, and reduces the need for multiple administrations.

\section{Conclusions and Prospects}

The unique "sandwich" structure of montmorillonite can not only interlock with polymer molecular chains to enhance the mechanical properties of the polymer but also can be exfoliated into graphene-like nanosheets to uniformly disperse and enhance the mechanical properties of the polymer. For the interlayer space of polymer molecular chain intercalation MMT, firstly, under the complex action of MMT and water molecules, the basic distance between the interlayer space increases. Then, one end of the polymer molecular chain forms a bond with the MMT under the action of electrostatic force or van der Waals force, while the other end forms a common compatibility with the polymer and finally forms an interlocking structure. Ball milling and ultrasound-assisted methods usually destroy the stability of the MMT structure and exfoliate it into a graphenelike nanosheet structure. The peeled MMT sheet not only has a higher aspect ratio but is also easier to be entangled with the polymer chain, so that the contact area of the polymer-MMT composite is increased, and the fracture consumes more energy. In addition, the exfoliated graphene-like montmorillonite nanosheets have a good effect on resisting crack propagation.

The organic modification of MMT includes surface graft modification and cation exchange modification. The modified MMT can not only achieve a surprising dispersion effect in the polymer matrix but also act as a compatibilizer to improve interfacial compatibility, providing an effective method for improving the performance of the polymer matrix. In addition, the organically modified MMT has abundant functional groups, providing a natural platform for drug loading and sustained drug release. The combination of these two aspects is of great significance to the development of ultra-high-performance and low-cost bone tissue engineering scaffolds.

Undoubtedly, montmorillonite has a positive effect on improving the performance of bone tissue engineering scaffolds. However, for polymer-MMT nanomaterials, researches on MMT functionalized bone tissue artificial scaffolds are in the ascendant. Firstly, more new assemblies of MMT nanomaterials and polymer materials should be discovered to provide more advanced functional materials for bone scaffolds. Secondly, more nontoxic and harmless modifiers should be developed, thereby paving the way for the preparation of polymer/MMT composite scaffolds with 
adjustable mechanical properties. Besides, we should deeply explore the potential of MMT for drug delivery in bone tissue engineering and build systematic drug-loading and drug release systems to provide support for the preparation of drug-loaded scaffolds with controllable release performance.

\section{Conflicts of Interest}

The authors declare that they have no conflicts of interest.

\section{Authors' Contributions}

DongYing Li and Pin Li contributed equally to this work.

\section{Acknowledgments}

This study was supported by the following funds: (1) Hunan Provincial Natural Science Foundation of China (2021JJ30632, 2020JJ4556); (2) Scientific Research Fund of Hunan Provincial Education Department (18A384, 19K083, 21B0686); (3) Graduate Research and Innovation Project of Shaoyang University (CX2020SY024, CX2020SY026, CX2020SY022).

\section{References}

[1] S. Pan, H. Yu, X. Yang et al., "Application of nanomaterials in stem cell regenerative medicine of orthopedic surgery," Journal of Nanomaterials, vol. 2017, Article ID 1985942, 12 pages, 2017.

[2] A. J. Rahyussalim, A. F. Marsetio, I. Saleh, T. Kurniawati, and Y. Whulanza, "The needs of current implant technology in orthopaedic prosthesis biomaterials application to reduce prosthesis failure rate," Journal of Nanomaterials, vol. 2016, 9 pages, 2016.

[3] G. Ye, F. Bao, X. Zhang et al., "Nanomaterial-based scaffolds for bone tissue engineering and regeneration," Nanomedicine, vol. 15, no. 20, pp. 1995-2017, 2020.

[4] R. Windhager, G. Hobusch, and M. Matzner, "Allogeneic transplants for biological reconstruction of bone defects," Der Orthopade, vol. 46, no. 8, pp. 656-664, 2017.

[5] P. Chocholata, V. Kulda, and V. Babuska, "Fabrication of scaffolds for bone-tissue regeneration," Materials, vol. 12, no. 4 , p. $568,2019$.

[6] A. Gholami, S. A. Hashemi, K. Yousefi et al., "3D nanostructures for tissue engineering, cancer therapy, and gene delivery," Journal of Nanomaterials, vol. 2020, 24 pages, 2020.

[7] M. A. Surmeneva, R. A. Surmenev, E. A. Chudinova et al., "Fabrication of multiple-layered gradient cellular metal scaffold via electron beam melting for segmental bone reconstruction," Materials \& Design, vol. 133, 2017.

[8] U. Cottino, F. Rosso, F. Dettoni, M. Bruzzone, D. E. Bonasia, and R. Rossi, "Treatment of bone losses in revision total hip and knee arthroplasty using trabecular metal: current literature," Journal of Nanomaterials, vol. 2016, 2016.

[9] F. S. Senatov, K. V. Niaza, M. Y. Zadorozhnyy, A. V. Maksimkin, S. D. Kaloshkin, and Y. Z. Estrin, "Mechanical properties and shape memory effect of 3D-printed PLA-based porous scaffolds," Journal of the Mechanical Behavior of Biomedical Materials, vol. 57, pp. 139-148, 2016.
[10] F. Sabir, M. I. Asad, M. Qindeel et al., "Polymeric nanogels as versatile nanoplatforms for biomedical applications," Journal of Nanomaterials, vol. 2019, Article ID 1526186, 16 pages, 2019.

[11] H. Shao, X. Ke, A. Liu et al., "Bone regeneration in 3D printing bioactive ceramic scaffolds with improved tissue/material interface pore architecture in thin-wall bone defect," Biofabrication, vol. 9, no. 2, article 025003, 2017.

[12] C. Shuai, Y. Xu, P. Feng, L. Xu, S. Peng, and Y. Deng, "Coenhance bioactive of polymer scaffold with mesoporous silica and nano-hydroxyapatite," Journal of Biomaterials Science. Polymer Edition, vol. 30, no. 12, pp. 1097-1113, 2019.

[13] C. Shuai, Y. Xu, P. Feng, Z. Zhao, and Y. Deng, "Hybridization of graphene oxide and mesoporous bioactive glass: micro-space network structure enhance polymer scaffold," Journal of the Mechanical Behavior of Biomedical Materials, vol. 109, article 103827, 2020.

[14] N. Sultana, "Mechanical and biological properties of scaffold materials," in Functional 3D Tissue Engineering Scaffolds, Woodhead Publishing, 2018.

[15] Y. Wu and Y. Han, "3D functional scaffolds for tendon tissue engineering," in Functional 3D Tissue Engineering Scaffolds, Woodhead Publishing, 2018.

[16] E. Mancuso, N. Alharbi, O. A. Bretcanu et al., "Three-dimensional printing of porous load-bearing bioceramic scaffolds," Proceedings of the Institution of Mechanical Engineers, Part H: Journal of Engineering in Medicine, vol. 231, no. 6, pp. 575-585, 2017.

[17] P. Feng, P. Wu, C. Gao et al., "A multimaterial scaffold with tunable properties: toward bone tissue repair," Advanced Science, vol. 5, no. 6, article 1700817, 2018.

[18] V. Guarino, V. Benfenati, I. Cruz-Maya, E. Saracino, R. Zamboni, and L. Ambrosio, "Instructive proteins for tissue regeneration," in Functional 3D Tissue Engineering Scaffolds, Woodhead Publishing, 2018.

[19] A. Roy, M. Joshi, B. S. Butola, and A. Srivastava, "Silverloaded HDPE/clay nanocomposites with antibacterial property: a potential replacement for commodity polyethylene plastic," Polymer Composites, vol. 39, pp. E366-E377, 2018.

[20] S. Jayrajsinh, G. Shankar, Y. K. Agrawal, and L. Bakre, "Montmorillonite nanoclay as a multifaceted drug-delivery carrier: a review," Journal of Drug Delivery Science and Technology, vol. 39, pp. 200-209, 2017.

[21] Q. Wu, Z. Que, Z. Li et al., "Photodegradation of ciprofloxacin adsorbed in the intracrystalline space of montmorillonite," Journal of Hazardous Materials, vol. 359, pp. 414-420, 2018.

[22] L. Peña-Parás, J. A. Sánchez-Fernández, and R. Vidaltamayo, "Nanoclays for Biomedical Applications," in Handbook of Ecomaterials, Springer International Publishing, 2019.

[23] T. T. Zhu, C. H. Zhou, F. B. Kabwe, Q. Q. Wu, C. S. Li, and J. R. Zhang, "Exfoliation of montmorillonite and related properties of clay/polymer nanocomposites," Applied Clay Science, vol. 169, pp. 48-66, 2019.

[24] A. Koç Demir, A. E. Elçin, and Y. M. Elçin, "Strontium-modified chitosan/montmorillonite composites as bone tissue engineering scaffold," Materials Science and Engineering: C, vol. 89, pp. 8-14, 2018.

[25] O. Alekseeva, A. Noskov, E. Grishina et al., "Structural and thermal properties of montmorillonite/ionic liquid composites," Materials, vol. 12, no. 16, p. 2578, 2019. 
[26] P. C. Mayekar, E. Castro-Aguirre, R. Auras, S. Selke, and R. Narayan, "Effect of nano-clay and surfactant on the biodegradation of poly (lactic acid) films," Polymers, vol. 12, no. 2, p. 311, 2020.

[27] F. Xiao, B.-Q. Yan, X.-Y. Zou et al., "Study on ionic liquid modified montmorillonite and molecular dynamics simulation," Colloids and Surfaces A: Physicochemical and Engineering Aspects, vol. 587, article 124311, 2020.

[28] J. García-Barrasa, J. López-de-Luzuriaga, and M. Monge, "Silver nanoparticles: synthesis through chemical methods in solution and biomedical applications," Open Chemistry, vol. 9, no. 1, pp. 7-19, 2011.

[29] S. P. Tesson, M. Salanne, B. Rotenberg, S. Tazi, and V. Marry, "Classical polarizable force field for clays: pyrophyllite and talc," The Journal of Physical Chemistry C, vol. 120, no. 7, pp. 3749-3758, 2016.

[30] N. Bumbudsanpharoke and S. Ko, "Nanoclays in food and beverage packaging," Journal of Nanomaterials, vol. 2019, 2019.

[31] S. Filippi, M. Cappello, M. Merce, and G. Polacco, "Effect of nanoadditives on bitumen aging resistance: a critical review," Journal of Nanomaterials, vol. 2018, 2018.

[32] G. Thakur, A. Singh, and I. Singh, "Chitosan-montmorillonite polymer composites: formulation and evaluation of sustained release tablets of aceclofenac," Scientia Pharmaceutica, vol. 84, no. 4, pp. 603-617, 2016.

[33] B. Biswas, L. N. Warr, E. F. Hilder et al., "Biocompatible functionalisation of nanoclays for improved environmental remediation," Chemical Society Reviews, vol. 48, no. 14, pp. 37403770, 2019.

[34] X. Zhang, H. Wang, Z. Liu et al., "Fabrication of durable fluorine-free superhydrophobic polyethersulfone (PES) composite coating enhanced by assembled MMT-SiO2 nanoparticles," Applied Surface Science, vol. 396, pp. 1580-1588, 2017.

[35] Y. Pei Ling, C.-H. Ooi, A. Matsumoto, and F.-Y. Yeoh, "Properties evaluation and fabrication of green clay reformulated from water sludge," Ceramics International, vol. 44, no. 2, pp. 1411-1419, 2018.

[36] A. Terzić, L. Pezo, L. Andrić, V. B. Pavlović, and V. V. Mitić, "Optimization of bentonite clay mechano-chemical activation using artificial neural network modeling," Ceramics International, vol. 43, no. 2, pp. 2549-2562, 2017.

[37] Z. K. Cui, S. Kim, J. J. Baljon, B. M. Wu, T. Aghaloo, and M. Lee, "Microporous methacrylated glycol chitosanmontmorillonite nanocomposite hydrogel for bone tissue engineering," Nature Communications, vol. 10, no. 1, 2019.

[38] S.-L. Bee, M. Abdullah, S.-T. Bee, L. T. Sin, and A. Rahmat, "Polymer nanocomposites based on silylated-montmorillonite: a review," Progress in Polymer Science, vol. 85, pp. 57-82, 2018.

[39] S. Gul, A. Kausar, B. Muhammad, and S. Jabeen, “Technical relevance of epoxy/clay nanocomposite with organically modified montmorillonite: a review," Polymer-Plastics Technology and Engineering, vol. 55, no. 13, pp. 13931415, 2016.

[40] A. Hermenean, A. Codreanu, H. Herman et al., "Chitosangraphene oxide $3 \mathrm{D}$ scaffolds as promising tools for bone regeneration in critical-size mouse calvarial defects," Scientific Reports, vol. 7, no. 1, article 16641, 2017.

[41] A. Karimi and W. M. A. Wan Daud, "Materials, preparation, and characterization ofPVA/MMTnanocomposite hydrogels: a review," Polymer Composites, vol. 38, no. 6, pp. 1086-1102, 2017.

[42] Q. Chen, R. Zhu, L. Ma, Q. Zhou, J. Zhu, and H. He, "Influence of interlayer species on the thermal characteristics of montmorillonite," Applied Clay Science, vol. 135, pp. 129-135, 2017.

[43] M. Bhattacharya, "Polymer nanocomposites-a comparison between carbon nanotubes, graphene, and clay as nanofillers," Materials, vol. 9, no. 4, p. 262, 2016.

[44] Y. Meng, B. Zhang, J. Su, and J. Han, "Preparation, characterization and properties of montmorillonite modified PTFE/ glass fiber composites," Fibers and Polymers, vol. 21, no. 5, pp. 1126-1133, 2020.

[45] T. Bai, B. Zhu, H. Liu et al., "Biodegradable poly(lactic acid) nanocomposites reinforced and toughened by carbon nanotubes/clay hybrids," International Journal of Biological Macromolecules, vol. 151, pp. 628-634, 2020.

[46] M. Ul-Islam, T. Khan, and J. K. Park, "Nanoreinforced bacterial cellulose-montmorillonite composites for biomedical applications," Carbohydrate Polymers, vol. 89, no. 4, pp. 1189-1197, 2012

[47] S. Noori, M. Kokabi, and Z. M. Hassan, "Nanoclay enhanced the mechanical properties of poly(vinyl alcohol) /chitosan /montmorillonite nanocomposite hydrogel as wound dressing," Procedia Materials Science, vol. 11, pp. 152-156, 2015.

[48] C. Shuai, Y. Li, P. Feng, W. Yang, Z. Zhao, and W. Liu, "Montmorillonite reduces crystallinity of poly-l-lactic acid scaffolds to accelerate degradation," Polymers for Advanced Technologies, vol. 30, no. 9, pp. 2425-2435, 2019.

[49] C. Shuai, L. Yu, P. Feng et al., "Organic montmorillonite produced an interlayer locking effect in a polymer scaffold to enhance interfacial bonding," Materials Chemistry Frontiers, vol. 4, no. 8, pp. 2398-2408, 2020.

[50] K. S. Katti, D. R. Katti, and R. Dash, "Synthesis and characterization of a novel chitosan/montmorillonite/hydroxyapatite nanocomposite for bone tissue engineering," Biomedical Materials, vol. 3, no. 3, article 034122, 2008.

[51] A. Olad, H. Bakht Khosh Hagh, A. Mirmohseni, and F. Farshi Azhar, "Graphene oxide and montmorillonite enriched natural polymeric scaffold for bone tissue engineering," Ceramics International, vol. 45, no. 12, pp. 15609-15619, 2019.

[52] N. Mauro, F. Chiellini, C. Bartoli et al., "RGD-mimic polyamidoamine-montmorillonite composites with tunable stiffness as scaffolds for bone tissue-engineering applications," Journal of Tissue Engineering and Regenerative Medicine, vol. 11, no. 7, pp. 2164-2175, 2017.

[53] C. Paluszkiewicz, E. Stodolak, M. Hasik, and M. Blazewicz, "FT-IR study of montmorillonite-chitosan nanocomposite materials," Spectrochimica Acta Part A: Molecular and Biomolecular Spectroscopy, vol. 79, no. 4, pp. 784-788, 2011.

[54] H. M. Ng, S.-T. Bee, L. T. Sin, C. Ratnam, and A. Rahmat, "Interaction effect of Scomberomorus guttatus-derived hydroxyapatite and montmorillonite on the characteristics of polylactic acid blends for biomedical application," Journal of Polymer Research, vol. 27, no. 8, pp. 1-24, 2020.

[55] M. Ionita, M. A. Pandele, and H. Iovu, "Sodium alginate/graphene oxide composite films with enhanced thermal and mechanical properties," Carbohydrate Polymers, vol. 94, no. 1, pp. 339-344, 2013.

[56] V. Guarino, V. Benfenati, I. Cruz-Maya, A. I. BorracheroConejo, R. Zamboni, and L. Ambrosio, "Bioinspired scaffolds 
for bone and neural tissue and interface engineering," in Functional 3D Tissue Engineering Scaffolds, Woodhead Publishing, 2018.

[57] C. Shuai, L. Yu, P. Feng, C. Gao, and S. Peng, "Interfacial reinforcement in bioceramic/biopolymer composite bone scaffold: the role of coupling agent," Colloids and Surfaces B, Biointerfaces, vol. 193, article 111083, 2020.

[58] J. P. Zheng, L. F. Xi, and H. Yao, "Correlation between reaction environment and intercalation effect in the synthesis of gelatin/montmorillonite hybrid nanocomposite," Journal of Materials Science Letters, vol. 22, no. 17, pp. 1179-1181, 2003.

[59] J. P. Zheng, C. Z. Wang, X. X. Wang, H. Y. Wang, H. Zhuang, and K. D. Yao, "Preparation of biomimetic three-dimensional gelatin/montmorillonite-chitosan scaffold for tissue engineering," Reactive and Functional Polymers, vol. 67, no. 9, pp. 780-788, 2007.

[60] Y. H. Lee, J. H. Lee, I. G. An et al., "Electrospun dual-porosity structure and biodegradation morphology of montmorillonite reinforced PLLA nanocomposite scaffolds," Biomaterials, vol. 26, no. 16, pp. 3165-3172, 2005.

[61] A. Ali, S. Bano, S. S. Poojary, D. Kumar, and Y. S. Negi, "Effect of incorporation of montmorillonite on Xylan/chitosan conjugate scaffold," Colloids and Surfaces B: Biointerfaces, vol. 180, pp. 75-82, 2019.

[62] U. Chatterjee, B. S. Butola, and M. Joshi, "High energy ball milling for the processing of organo-montmorillonite in bulk," Applied Clay Science, vol. 140, pp. 10-16, 2017.

[63] H. Li, Y. Zhao, S. Song, and Y. Nahmad, "Comparison of ultrasound treatment with mechanical shearing for montmorillonite exfoliation in aqueous solutions," Journal of Minerals and Materials Research, vol. 2, no. 1, pp. 1-12, 2015.

[64] A. R. A. Hamid, A. F. Osman, D. Martin, Y. M. Daud, M. A. B. Abdullah, and C. M. R. Ghazali, "Effect of dispersant concentration on morphology of the ultrasonicated organically modified montmorillonite," in Proc. Mecha. Eng. Research Day, pp. 354-355, 2017.

[65] T. Chen, Y. Yuan, Y. Zhao, F. Rao, and S. Song, "Preparation of montmorillonite nanosheets through freezing/thawing and ultrasonic exfoliation," Langmuir, vol. 35, no. 6, pp. 2368-2374, 2019.

[66] Z. Cherifi, B. Boukoussa, A. Zaoui, M. Belbachir, and R. Meghabar, "Structural, morphological and thermal properties of nanocomposites poly (GMA)/clay prepared by ultrasound and in-situ polymerization," Ultrasonics Sonochemistry, vol. 48, pp. 188-198, 2018.

[67] O. Zabihi, M. Ahmadi, and M. Naebe, "Self-assembly of quaternized chitosan nanoparticles within nanoclay layers for enhancement of interfacial properties in toughened polymer nanocomposites," Materials \& Design, 2017.

[68] K. Strawhecker and E. Manias, "Structure and properties of poly (vinyl alcohol)/Na+ montmorillonite nanocomposites," Chemistry of Materials, vol. 12, no. 10, pp. 2943-2949, 2000.

[69] K. Kowalczyk, T. Spychaj, A. Ubowska, and B. Schmidt, "Industrially applicable methods of poly(methyl methacrylate)/organophilic montmorillonite nanocomposites preparation: processes and cast materials characterization," Applied Clay Science, vol. 97-98, pp. 96-103, 2014.

[70] A. F. Osman, A. M. Alakrach, H. Kalo, W. Azmi, and F. Hashim, "In vitro biostability and biocompatibility of ethyl vinyl acetate (EVA) nanocomposites for biomedical applications," RSC Advances, vol. 5, no. 40, pp. 31485-31495, 2015.
[71] S. Sharma, M. Kumar Poddar, and V. S. Moholkar, "Enhancement of thermal and mechanical properties of poly(MMA-co-BA)/Cloisite 30B nanocomposites by ultrasound-assisted in-situ emulsion polymerization," Ultrasonics Sonochemistry, vol. 36, article S1350417716304163, 225 pages, 2017.

[72] S. Habibi, M. Saket, H. Nazockdast, and K. Hajinasrollah, "Fabrication and characterization of exfoliated chitosan-gelatin-montmorillonite nanocomposite nanofibers," The Journal of The Textile Institute, vol. 110, no. 11, pp. 1672-1677, 2019.

[73] Y. Xu, D. Gao, P. Feng et al., "A mesoporous silica composite scaffold: cell behaviors, biomineralization and mechanical properties," Applied Surface Science, vol. 423, pp. 314-321, 2017.

[74] Y. Xu, P. Wu, P. Feng, W. Guo, W. Yang, and C. Shuai, "Interfacial reinforcement in a poly-l-lactic acid/mesoporous bioactive glass scaffold via polydopamine," Colloids and Surfaces. B, Biointerfaces, vol. 170, pp. 45-53, 2018.

[75] J. H. Xu, T. Liu, Y. Zhang et al., "Dragonfly wing-inspired architecture makes a stiff yet tough healable material," Matter, vol. 4, no. 7, pp. 2474-2489, 2021.

[76] J. Long, J. Zhang, and M. P. Wolcott, "Comparison of polylactide/nano-sized calcium carbonate and polylactide/ montmorillonite composites: reinforcing effects and toughening mechanisms," Polymer, vol. 48, no. 26, pp. 7632 7644, 2007.

[77] X. Wang, Q. Su, J. Shan, and J. Zheng, "The effect of clay modification on the mechanical properties of poly(methyl methacrylate)/organomodified montmorillonite nanocomposites prepared by in situ suspension polymerization," Polymer Composites, vol. 37, no. 6, pp. 1705-1714, 2016.

[78] M. A. Gunning, L. M. Geever, J. A. Killion, J. G. Lyons, and C. L. Higginbotham, "Mechanical and biodegradation performance of short natural fibre polyhydroxybutyrate composites," Polymer Testing, vol. 32, no. 8, pp. 1603-1611, 2013.

[79] G. Zhang, T. Wu, W. Lin et al., "Preparation of polymer/clay nanocomposites via melt intercalation under continuous elongation flow," Composites Science and Technology, vol. 145, pp. 157-164, 2017.

[80] R. Nawang, M. Z. Hussein, K. A. Matori, C. A. Che Abdullah, and M. Hashim, "Physicochemical properties of hydroxyapatite/montmorillonite nanocomposite prepared by powder sintering," Results in Physics, vol. 15, article 102540, 2019.

[81] G. B. B. Varadwaj, K. Parida, and V. O. Nyamori, "Transforming inorganic layered montmorillonite into inorganicorganic hybrid materials for various applications: a brief overview," Inorganic Chemistry Frontiers, vol. 3, no. 9, pp. 1100-1111, 2016.

[82] G. Kapusetti, N. Misra, V. Singh et al., "Bone cement based nanohybrid as a super biomaterial for bone healing," Journal of Materials Chemistry B, vol. 2, no. 25, pp. 3984-3997, 2014.

[83] B. Zhu, Y. Wang, H. Liu, J. Ying, C. Liu, and C. Shen, "Effects of interface interaction and microphase dispersion on the mechanical properties of PCL/PLA/MMT nanocomposites visualized by nanomechanical mapping," Composites Science and Technology, vol. 190, article 108048, 2020.

[84] R. S. Mohammadi, A. M. Zolali, S. H. Tabatabaei, and A. Ajji, "Interfacial localization of organoclay enhances the peelability of polyethylene/polybutene-1/organoclay nanocomposite films," Composites Part B: Engineering, vol. 218, 2021. 
[85] S. Pramanik, P. Bharali, B. K. Konwar, and N. Karak, "Antimicrobial hyperbranched poly(ester amide)/polyaniline nanofiber modified montmorillonite nanocomposites," Materials Science \& Engineering. C, Materials for Biological Applications, vol. 35, pp. 61-69, 2014.

[86] B. Zhu, X. Wang, Q. Zeng et al., "Enhanced mechanical properties of biodegradable poly( $\varepsilon$-caprolactone)/cellulose acetate butyrate nanocomposites filled with organoclay," Composites Communications, vol. 13, pp. 70-74, 2019.

[87] L. N. Carli, J. S. Crespo, and R. S. Mauler, "PHBV nanocomposites based on organomodified montmorillonite and halloysite: the effect of clay type on the morphology and thermal and mechanical properties," Composites Part A: Applied Science and Manufacturing, vol. 42, no. 11, pp. 1601-1608, 2011.

[88] A. H. Ambre, K. S. Katti, and D. R. Katti, "Nanoclay based composite scaffolds for bone tissue engineering applications," Journal of Nanotechnology in Engineering and Medicine, vol. 1, no. 3, 2010.

[89] K. Fukushima, D. Tabuani, M. Arena, M. Gennari, and G. Camino, "Effect of clay type and loading on thermal, mechanical properties and biodegradation of poly(lactic acid) nanocomposites," Reactive and Functional Polymers, vol. 73, no. 3, pp. 540-549, 2013.

[90] Y. Zhao, S. L. Zhang, C. F. Zhang, Z. Zhou, and G. B. Wang, "Study on poly(ether ether ketone)/organically modified montmorillonite composites," Plastics, Rubber and Composites, vol. 38, no. 7, pp. 279-283, 2009.

[91] P. C. LeBaron, Z. Wang, and T. J. Pinnavaia, "Polymer-layered silicate nanocomposites: an overview," Applied Clay Science, vol. 15, no. 1-2, pp. 11-29, 1999.

[92] I. Carmagnola, E. Ranzato, and V. Chiono, "Scaffold functionalization to support a tissue biocompatibility," in Functional 3D Tissue Engineering Scaffolds, Woodhead Publishing, 2018.

[93] H. He, J. Duchet, J. Galy, and J. F. Gerard, "Grafting of swelling clay materials with 3-aminopropyltriethoxysilane," Journal of Colloid and Interface Science, vol. 288, no. 1, pp. 171176, 2005.

[94] A. M. Shanmugharaj, K. Y. Rhee, and S. H. Ryu, "Influence of dispersing medium on grafting of aminopropyltriethoxysilane in swelling clay materials," Journal of Colloid and Interface Science, vol. 298, no. 2, pp. 854-859, 2006.

[95] K. I. Tonle, E. Ngameni, D. Njopwouo, C. Carteret, and A. Walcarius, "Functionalization of natural smectite-type clays by grafting with organosilanes: physico-chemical characterization and application to mercury(II) uptake," Physical Chemistry Chemical Physics -Cambridge-Royal Society oOf Chemistry, vol. 5, no. 21, p. 4951, 2003.

[96] S. Zulfiqar, A. Kausar, M. Rizwan, and M. I. Sarwar, "Probing the role of surface treated montmorillonite on the properties of semi-aromatic polyamide/clay nanocomposites," Applied Surface Science, vol. 255, no. 5, pp. 2080-2086, 2008.

[97] L. Su, Q. Tao, H. He, J. Zhu, and P. Yuan, "Locking effect: a novel insight in the silylation of montmorillonite surfaces," Materials Chemistry and Physics, vol. 136, no. 2-3, pp. 292295, 2012.

[98] B. R. Venugopal, S. Sen, C. Shivakumara, and M. Rajamathi, "Delamination of surfactant intercalated smectites in alcohols: effect of chain length of the solvent," Applied Clay Science, vol. 32, no. 1-2, pp. 141-146, 2006.
[99] H. Khosravi and R. Eslami-Farsani, "Enhanced mechanical properties of unidirectional basalt fiber/epoxy composites using silane-modified Na+-montmorillonite nanoclay," Polymer Testing, vol. 55, pp. 135-142, 2016.

[100] U. Szeluga, B. Kumanek, and B. Trzebicka, "Synergy in hybrid polymer/nanocarbon composites. A review," Composites, Part A Applied Science and Manufacturing, vol. 73, pp. 204-231, 2015.

[101] M. Darder, P. Aranda, C. Ruiz-Garcia, F. M. Fernandes, and E. Ruiz-Hitzky, "The meeting point of carbonaceous materials and clays: toward a new generation of functional composites," Advanced Functional Materials, vol. 28, no. 27, 2018.

[102] E. Ruiz-Hitzky, M. Sobral, A. Gómez-Avilés et al., "Clay-graphene nanoplatelets functional conducting composites," Advanced Functional Materials, vol. 26, no. 41, pp. 73947405, 2016.

[103] D. L. D. Wu, D. Lin, J. Zhang et al., "Selective localization of nanofillers: effect on morphology and crystallization of PLA/ PCL blends," Macromolecular Chemistry and Physics, vol. 212, no. 6, pp. 613-626, 2011.

[104] B. Zhu, T. Bai, P. Wang, Y. Wang, C. Liu, and C. Shen, "Selective dispersion of carbon nanotubes and nanoclay in biodegradable poly( $\varepsilon$-caprolactone)/poly(lactic acid) blends with improved toughness, strength and thermal stability," International Journal of Biological Macromolecules, vol. 153, pp. 1272-1280, 2020.

[105] W. D. Zhang, I. Y. Phang, and T. Liu, "Growth of carbon nanotubes on clay: unique nanostructured filler for highperformance polymer nanocomposites," Advanced Materials, vol. 18, no. 1, pp. 73-77, 2006.

[106] C. Zhang, W. W. Tjiu, T. Liu, W. Y. Lui, I. Y. Phang, and W. D. Zhang, "Dramatically enhanced mechanical performance of Nylon-6 magnetic composites with nanostructured hybrid one-dimensional carbon nanotube?Two-dimensional clay nanoplatelet heterostructures," Journal of Physical Chemistry B, vol. 115, no. 13, pp. 3392-3399, 2011.

[107] L. J. Michot, I. Bihannic, F. Thomas et al., "Coagulation of Na-montmorillonite by inorganic cations at neutral $\mathrm{pH}$. A combined transmission X-ray microscopy, small angle and wide angle X-ray scattering study," Langmuir, vol. 29, no. 10, pp. 3500-3510, 2013.

[108] W. H. Yu, Q. Q. Ren, D. S. Tong, C. H. Zhou, and H. Wang, "Clean production of CTAB-montmorillonite: formation mechanism and swelling behavior in xylene," Applied Clay Science, vol. 97-98, pp. 222-234, 2014.

[109] D. J. Zhou, Z. Zhang, J. Tang, M. Zhang, and L. Liao, "Effects of variables on the dispersion of cationic-anionic organomontmorillonites and characteristics of Pickering emulsion," RSC Advances, vol. 6, no. 12, pp. 9678-9685, 2016.

[110] G. Lazorenko, A. Kasprzhitskii, and V. Yavna, "Synthesis and structural characterization of betaine- and imidazoline-based organoclays," Chemical Physics Letters, vol. 692, pp. 264-270, 2018.

[111] A. Ahmed, Y. Chaker, E. H. Belarbi et al., "XRD and ATR/ FTIR investigations of various montmorillonite clays modified by monocationic and dicationic imidazolium ionic liquids," Journal of Molecular Structure, vol. 1173, pp. 653664, 2018.

[112] S. Peng, T. Mao, C. Zheng et al., "Polyhydroxyl gemini surfactant-modified montmorillonite for efficient removal of methyl orange," Colloids and Surfaces A: Physicochemical and Engineering Aspects, vol. 578, article 123602, 2019. 
[113] W. Luo, J. Ouyang, P. Antwi, M. Wu, Z. Huang, and W. Qin, "Corrigendum to "Microwave/ultrasound-assisted modification of montmorillonite by conventional and gemini alkyl quaternary ammonium salts for adsorption of chromate and phenol: Structure-function relationship" [Sci. Total Environ. 655 (2019) 1104-1112]," Science of the Total Environment, vol. 674, p. 26, 2019.

[114] A. M. Atta, H. A. Al-Lohedan, Z. A. Alothman, A. M. Tawfeek, A. Abdelghafar, and N. A. Hamad, "Effect of zeta potential of exfoliated amphiphilic montmorillonite nanogels on removal efficiencies of cationic dye water pollutant," International Journal of Electrochemical Science, vol. 11, no. 5, pp. 3786-3802, 2016.

[115] H. Behniafar, A. Ahmadi-khaneghah, and M. Yazdi, "Enhanced heat stability and storage modulus in novel PTMO-intercalated clay platelets/PTMO-based polyurethane nanocomposites," Journal of Polymer Research, vol. 23, no. 9, pp. 1-10, 2016.

[116] X. Wang, Q. Su, J. Shan, and J. Zheng, “The effect of clay modification on the mechanical properties of poly(methyl methacrylate)/organomodified montmorillonite nanocomposites prepared byin sitususpension polymerization," Polymer Composites, vol. 37, no. 6, pp. 1705-1714, 2016.

[117] R. Hojiyev, Y. Ulcay, M. S. Çelik, and W. M. Carty, "Effect of CEC coverage of hexadecyltributylphosphonium modified montmorillonite on polymer compatibility," Applied Clay Science, vol. 141, pp. 204-211, 2017.

[118] M. Beltrán, V. Benavente, V. Marchante, H. Dema, and A. Marcilla, "Characterisation of montmorillonites simultaneously modified with an organic dye and an ammonium salt at different dye/salt ratios. Properties of these modified montmorillonites EVA nanocomposites," Applied Clay Science, vol. 97-98, pp. 43-52, 2014.

[119] F. M. Flores, T. Undabeytia, E. Morillo, and R. M. Torres Sánchez, "Technological applications of organomontmorillonites in the removal of pyrimethanil from water: adsorption/desorption and flocculation studies," Environmental Science \& Pollution Research, vol. 24, no. 16, pp. 14463-14476, 2017.

[120] G. Wang, S. Zhang, Y. Hua et al., "Phenol and/or $\mathrm{Zn}^{2+}$ adsorption by single- or dual-cation organomontmorillonites," Applied Clay Science, vol. 140, pp. 1-9, 2017.

[121] G. Zhuang, Z. Zhang, H. Wu, H. Zhang, X. Zhang, and L. Liao, "Influence of the Nonionic surfactants' Nature on the Structures and Properties of Organo-Montmorillonites," Colloids \& Surfaces A Physicochemical \& Engineering Aspects, vol. 518, pp. 116-123, 2017.

[122] H. He, Y. Ma, J. Zhu, P. Yuan, and Y. Qing, "Organoclays prepared from montmorillonites with different cation exchange capacity and surfactant configuration," Applied Clay Science, vol. 48, no. 1-2, pp. 67-72, 2010.

[123] P. M. Naranjo, E. L. Sham, and E. M. Farfán Torres, “Characterization of hexadecyltrimethylammonium-organoclay and its individual components by thermal techniques," Bulletin of Materials Science, vol. 40, no. 4, pp. 753-758, 2017.

[124] H. Ghasemi Hamidabadi, Z. Rezvani, M. Nazm Bojnordi et al., "Chitosan-intercalated montmorillonite/poly (vinyl alcohol) nanofibers as a platform to guide neuronlike differentiation of human dental pulp stem cells," ACS Applied Materials \& Interfaces, vol. 9, no. 13, pp. 11392-11404, 2017.

[125] M. Koosha, H. Mirzadeh, M. A. Shokrgozar, and M. Farokhi, "Nanoclay-reinforced electrospun chitosan/PVA nanocom- posite nanofibers for biomedical applications," RSC Advances, vol. 5, no. 14, pp. 10479-10487, 2015.

[126] A. Koç Demir, "Development and characterization of gelatine/chitosan/montmorillonite composite scaffold enriched with magnesium," Revue Roumaine de Chimie, vol. 64, no. 4, pp. 327-334, 2019.

[127] A. K. Gaharwar, S. Mukundan, E. Karaca et al., "Nanoclayenriched poly ( $\varepsilon$-caprolactone) electrospun scaffolds for osteogenic differentiation of human mesenchymal stem cells," Tissue Engineering Part A, vol. 20, no. 15-16, pp. 20882101, 2014.

[128] A. Koç Demir, "Development and characterization of zincincorporated montmorillonite/poly ( $\varepsilon$-caprolactone) composite scaffold for osteogenic tissue-engineering applications," Polymer Composites, vol. 39, pp. E601-E608, 2018.

[129] K. Kundu, A. Afshar, D. R. Katti, M. Edirisinghe, and K. S. Katti, "Composite nanoclay-hydroxyapatite-polymer fiber scaffolds for bone tissue engineering manufactured using pressurized gyration," Composites Science and Technology, vol. 202, 2021.

[130] G.-J. Kim, D. Kim, K.-J. Lee et al., "Effect of nanomontmorillonite on osteoblast differentiation, mineral density, and osteoclast differentiation in bone formation," Nanomaterials, vol. 10, no. 2, p. 230, 2020.

[131] L. Yu, Y. Liu, P. Feng, C. Shuai, S. Peng, and A. Min, "Organically modified montmorillonite improves interfacial compatibility between PLLA and PGA in bone scaffold," Polymer Degradation and Stability, vol. 182, 2020.

[132] M. S. Islam, M. S. Rahaman, and J. H. Yeum, "Electrospun novel super-absorbent based on polysaccharide-polyvinyl alcohol-montmorillonite clay nanocomposites," Carbohydrate Polymers, vol. 115, pp. 69-77, 2015.

[133] K. Fukushima, A. Rasyida, and M.-C. Yang, "Characterization, degradation and biocompatibility of PBAT based nanocomposites," Applied Clay Science, vol. 80-81, pp. 291-298, 2013.

[134] S. Lal, A. Perwez, M. A. Rizvi, and M. Datta, "Design and development of a biocompatible montmorillonite PLGA nanocomposites to evaluate in vitro oral delivery of insulin," Applied Clay Science, vol. 147, pp. 69-79, 2017.

[135] I. Salcedo, C. Aguzzi, G. Sandri et al., "In vitro biocompatibility and mucoadhesion of montmorillonite chitosan nanocomposite: a new drug delivery," Applied Clay Science, vol. 55, pp. 131-137, 2012.

[136] S.-H. Hsu, M.-C. Wang, and J.-J. Lin, "Biocompatibility and antimicrobial evaluation of montmorillonite/chitosan nanocomposites," Applied Clay Science, vol. 56, pp. 53-62, 2012.

[137] A. G. Sabzevari, H. Sabahi, and M. Nikbakht, "Montmorillonite, a natural biocompatible nanosheet with intrinsic antitumor activity," Colloids and Surfaces. B, Biointerfaces, vol. 190, article 110884, 2020.

[138] D. Briesenick and W. Bremser, "Synthesis of polyamideimide-montmorillonite-nanocomposites via new approach of in situ polymerization and solvent casting," Progress in Organic Coatings, vol. 82, pp. 26-32, 2015.

[139] B. K. Bozolan, O. Duman, and S. Tun, "Smart antifungal thermosensitive chitosan/carboxymethylcellulose/scleroglucan/ montmorillonite nanocomposite hydrogels for onychomycosis treatment," Colloids and Surfaces A Physicochemical and Engineering Aspects, vol. 610, article 125600, 2020.

[140] M. Liu, H. Zheng, J. Chen, S. Li, J. Huang, and C. Zhou, "Chitosan-chitin nanocrystal composite scaffolds for tissue 
engineering," Carbohydrate Polymers, vol. 152, pp. 832-840, 2016.

[141] S. S. Mohd, M. A. A. Abdullah, and K. A. Mat Amin, "Gellan gum/clay hydrogels for tissue engineering application: mechanical, thermal behavior, cell viability, and antibacterial properties," Journal of Bioactive and Compatible Polymers, vol. 31, no. 6, pp. 648-666, 2016.

[142] M. Li, P. He, Y. Wu et al., "Stimulatory effects of the degradation products from $\mathrm{Mg}$-Ca-Sr alloy on the osteogenesis through regulating ERK signaling pathway," Scientific Reports, vol. 6, no. 1, 2016.

[143] M. Salas-Orozco, N. Niño-Martínez, G.-A. Martínez-Castañón, F. T. Méndez, M. E. C. Jasso, and F. Ruiz, "Mechanisms of resistance to silver nanoparticles in endodontic bacteria: a literature review," Journal of Nanomaterials, vol. 2019, Article ID 7630316, 11 pages, 2019.

[144] M. Horue, M. L. Cacicedo, M. A. Fernandez, B. RodenakKladniew, R. M. Torres Sánchez, and G. R. Castro, "Antimicrobial activities of bacterial cellulose - Silver montmorillonite nanocomposites for wound healing," Materials Science and Engineering: $C$, vol. 116, article 111152, 2020.

[145] D. L. S. Bonga, M. Pinto, and M. F. T. Tayad, "Synthesis and characterization of silver nanoparticles anchored on montmorillonite via chemical reduction," in Nano Hybrids and Composites, pp. 30-37, Trans Tech Publ, 2016.

[146] S. Dawadi, S. Katuwal, A. Gupta et al., "Current research on silver nanoparticles: synthesis, characterization, and applications," Journal of Nanomaterials, vol. 2021, 2021.

[147] Y. Xu, Y. Hu, P. Feng, W. Yang, and C. Shuai, "Drug loading/ release and bioactivity research of a mesoporous bioactive glass/polymer scaffold," Ceramics International, vol. 45, no. 14, pp. 18003-18013, 2019.

[148] A. Sadeghianmaryan, Z. Yazdanpanah, Y. A. Soltani, H. A. Sardroud, M. H. Nasirtabrizi, and X. Chen, "Curcuminloaded electrospun polycaprolactone/montmorillonite nanocomposite: wound dressing application with anti-bacterial and low cell toxicity properties," Journal of Biomaterials Science, Polymer Edition, vol. 31, no. 2, pp. 169-187, 2020.

[149] C. Shuai, Y. Xu, P. Feng, G. Wang, S. Xiong, and S. Peng, "Antibacterial polymer scaffold based on mesoporous bioactive glass loaded with in situ grown silver," Chemical Engineering Journal, vol. 374, pp. 304-315, 2019.

[150] B. Nabil, E. A. Ahmida, C. Christine, V. Julien, and A. Abdelkrim, "Polyfunctional cotton fabrics with catalytic activity and antibacterial capacity," Chemical Engineering Journal, vol. 351, pp. 328-339, 2018.

[151] W. Guo, Y. Zhang, P. Feng et al., "Montmorillonite with unique interlayer space imparted polymer scaffolds with sustained release of Ag+," Ceramics International, vol. 45, no. 9, pp. 11517-11526, 2019.

[152] P. Costa and J. M. Sousa Lobo, "Modeling and comparison of dissolution profiles," European Journal of Pharmaceutical Sciences, vol. 13, no. 2, pp. 123-133, 2001.

[153] S. Dash, P. N. Murthy, L. Nath, and P. Chowdhury, "Kinetic modeling on drug release from controlled drug delivery systems," Acta Poloniae Pharmaceutica, vol. 67, no. 3, pp. 217223, 2010.

[154] T. Higuchi, "Mechanism of sustained-action medication. Theoretical analysis of rate of release of solid drugs dispersed in solid matrices," Journal of Pharmaceutical Sciences, vol. 52, no. 12, pp. 1145-1149, 1963.
[155] R. W. Korsmeyer, R. Gurny, E. Doelker, P. Buri, and N. A. Peppas, "Mechanisms of solute release from porous hydrophilic polymers," International Journal of Pharmaceutics, vol. 15, no. 1, pp. 25-35, 1983.

[156] Y. Panahi, A. Gharekhani, H. Hamishehkar, P. Zakeri-Milani, and H. Gharekhani, "Stomach-specific drug delivery of clarithromycin using a semi interpenetrating polymeric network hydrogel made of montmorillonite and chitosan: synthesis, characterization and in vitro drug release study," Advanced pharmaceutical bulletin, vol. 9, no. 1, pp. 159-173, 2019.

[157] T. Li, L. Zhao, Z. Zheng et al., "Design and preparation acidactivated montmorillonite sustained-release drug delivery system for dexibuprofen in vitro and in vivo evaluations," Applied Clay Science, vol. 163, pp. 178-185, 2018.

[158] P. L. Ritger and N. A. Peppas, "A simple equation for description of solute release II. Fickian and anomalous release from swellable devices," Journal of Controlled Release, vol. 5, no. 1, pp. 37-42, 1987.

[159] J. Siepmann and N. A. Peppas, "Modeling of drug release from delivery systems based on hydroxypropyl methylcellulose (HPMC)," Advanced Drug Delivery Reviews, vol. 64, pp. 163-174, 2012.

[160] N. Khatoon, M. Q. Chu, and C. H. Zhou, "Nanoclay-based drug delivery systems and their therapeutic potentials," Journal of Materials Chemistry B, vol. 8, no. 33, pp. 7335-7351, 2020.

[161] J. H. Park, H. J. Shin, M. H. Kim et al., "Application of montmorillonite in bentonite as a pharmaceutical excipient in drug delivery systems," Journal of Pharmaceutical Investigation, vol. 46, no. 4, pp. 363-375, 2016.

[162] T. S. Anirudhan and J. Parvathy, "Novel thiolated chitosanpolyethyleneglycol blend/montmorillonite composite formulations for the oral delivery of insulin," Bioactive Carbohydrates and Dietary Fibre, vol. 16, pp. 22-29, 2018.

[163] M. Kaur and M. Datta, "Diclofenac Sodium Adsorption onto Montmorillonite: Adsorption Equilibrium Studies and Drug Release Kinetics," Adsorption Science \& Technology, vol. 32, no. 5, pp. 365-387, 2014.

[164] F. Farshi Azhar and A. Olad, "A study on sustained release formulations for oral delivery of 5-fluorouracil based on alginate-chitosan/montmorillonite nanocomposite systems," Applied Clay Science, vol. 101, pp. 288-296, 2014.

[165] M. A. Djebbi, S. Boubakri, Z. Bouaziz et al., "Extended-release of chlorpromazine intercalated into montmorillonite clays," Microporous and Mesoporous Materials, vol. 267, pp. 43-52, 2018.

[166] H. Yan, X. Chen, C. Bao et al., "Synthesis and assessment of CTAB and NPE modified organo-montmorillonite for the fabrication of organo-montmorillonite/alginate based hydrophobic pharmaceutical controlled-release formulation," Colloids and Surfaces. B, Biointerfaces, vol. 191, article 110983, 2020.

[167] C. R. N. Jesus, E. F. Molina, S. H. Pulcinelli, and C. V. Santilli, "Highly controlled diffusion drug release from ureasil-poly(ethylene oxide)- $\mathrm{Na}(+)$-montmorillonite hybrid hydrogel nanocomposites," ACS Applied Materials \& Interfaces, vol. 10, no. 22, pp. 19059-19068, 2018.

[168] B. Gulen and P. Demircivi, "Synthesis and characterization of montmorillonite/ciprofloxacin/TiO2 porous structure for controlled drug release of ciprofloxacin tablet with oral administration," Applied Clay Science, vol. 197, 2020. 
[169] C. Luo, Q. Yang, X. Lin, C. Qi, and G. Li, "Preparation and drug release property of tanshinone IIA loaded chitosanmontmorillonite microspheres," International Journal of Biological Macromolecules, vol. 125, pp. 721-729, 2019.

[170] M. Al-Sahly, H. El-Hamshary, and S. S. Al-Deyab, "Impact of chain length on release behavior of modified polyethylene glycol intercalated-montmorillonite nanocomposite," Journal of Nanoscience and Nanotechnology, vol. 20, no. 9, pp. 5546-5554, 2020.

[171] Y. J. Meng, S. Y. Wang, Z. W. Guo, M. M. Cheng, J. Li, and D. Q. Li, "Design and preparation of quaternized pectinmontmorillonite hybrid film for sustained drug release," International Journal of Biological Macromolecules, vol. 154, pp. 413-420, 2020.

[172] L. Bounabi, N. B. Mokhnachi, N. Haddadine, F. Ouazib, and R. Barille, "Development of poly (2-hydroxyethyl methacrylate)/clay composites as drug delivery systems of paracetamol," Journal of Drug Delivery Science and Technology, vol. 33, pp. 58-65, 2016.

[173] L. G. Bakre, J. I. Sarvaiya, and Y. K. Agrawal, "Synthesis, characterization, and study of drug release properties of curcumin from polycaprolactone/organomodified montmorillonite nanocomposite," Journal of Pharmaceutical Innovation, vol. 11, no. 4, pp. 300-307, 2016.

[174] K. Yu, T. Zhu, Y. Wu et al., "Incorporation of amoxicillinloaded organic montmorillonite into poly (ester-urethane) urea nanofibers as a functional tissue engineering scaffold," Colloids and Surfaces B: Biointerfaces, vol. 151, pp. 314-323, 2017. 